\title{
Blockchain-Enabled Platforms: Challenges and Recommendations
}

\author{
M. Inmaculada García Sáez* \\ Warwick Business School (United Kingdom) \\ Received 23 March 2020 | Accepted 25 April 2020 | Published 26 August 2020
}

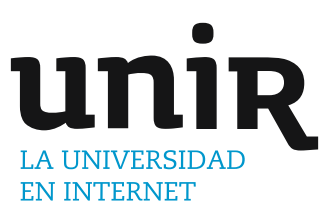

KEYWORDS

Adoption, Blockchain, Collaborative Networks Disruption, Value Proposition.
Not even a tenth of blockchain-enabled platforms survive their first anniversary. The volatility of cryptomarkets has brought negative attention and led some to question the applicability of blockchain technology. This paper argues that the challenges for startups and incumbents behind these platforms are numerous, and that the speculative bubble around cryptocurrencies is only one of them. Blockchain still needs to demonstrate fully its disruptive potential and so far, entrepreneurs have not managed to significantly impact incumbents' market shares. This transitory period requires incumbents to let go of traditional control mech-anisms, and startups to scale down their global decentralised hopes. Indeed, whilst the technology can indeed scale fast, starting in a controlled market and managing growth is a counterintuitive but essential strategy for blockchain-enabled platforms to implement. Given the diverging nature of the technology, at present at least, the combined shortage of skills in blockchain and security, and the trust blockchain is built on, rushing to the global market is high risk. Nonetheless, given the potential returns, the risk appetite is high and both entrepreneurs and corporate executives share unrealistic expectations about a technology they cannot fully understand since it has not yet converged. In light of the above, this article identifies the main challenges faced when building blockchainenabled platforms and provides recommendations for startups and incumbents to overcome these. In order to reach these conclusions, the information obtained from twenty semi-structured interviews with leading actors in the field has been fundamental.
DOI: $10.9781 /$ ijimai.2020.08.005

\section{INTRODUCTION}

TN the last decade, the unprecedented rate of disruptive digital innova-tion has raised concerns about the sustainability of today's firms, jobs and business models. It has also sparked a wide range of new oppor-tunities [1]. The emergence of platform businesses and the sharing economy has rapidly transformed industries, leveraging innovative business models that changed consumer preferences, from Airbnb to Uber.

The emergence of the sharing economy, the rise of platform businesses and the birth of bitcoin are closely intertwined with the global financial crisis in 2008 [1]-[3]. These developments offered a shift from traditional centralised systems, enabling peer-to-peer value exchanges with a shared interest to co-create alternative systems. In this context, the sharing economy had one major obstacle to disintermediate the access to resources that blockchain solves: trust.

"The one thing that's missing, but that will soon be developed, it's a reliable e-cash. A method where buying on the Internet you can transfer funds from A to B, without A knowing B or B knowing A" [4].

What blockchain promises, and what fuelled its popularity, is no less than the technological backbone of the 21 st century's renaissance of the social commons [5]: increase in transparency and horizontal

\footnotetext{
* Corresponding author.

E-mail address: inmaculadagarcia@gmail.com
}

cooperation, fair distribution of wealth and decrease in top-down governance, corruption, censorship or coercion [6]-[8].

Tetris, the popular game from the $90 \mathrm{~s}$, is a prime example of the world then: top-down, hierarchical, rigid rules, impossible to beat. Minecraft, a popular game nowadays, is all the contrary: bottom-up, players fall under no authority, do what they want and win all the time. With the explosion of social media and increased data leaks on corruption in centralised systems, social unrest is growing all over the world. In other words, people have a Minecraft mindset, but this is still very much a Tetris world [9]. Blockchain is the technology that makes a Minecraft world possible. Blockchain-enabled platforms are where this world will be created.

Indeed, by 2025 , ten percent of the global gross domestic product is expected to be stored on blockchain technology [10]. And blockchainenabled platforms will go beyond the main characteristics of the technology, from transparency to immutability, to actually reinvent the way we do business, the way we capture value and hopefully solve some of the world's societal challenges; in short, it can bring about a post-capitalist world.

However, the ability for blockchain to unleash the full potential of the Fourth Industrial Revolution, to design and govern more inclusive platforms that could create enough wealth to close the economic divide, is undermined by numerous adoption barriers [11]. In 2018, the average lifespan of a blockchain project was 1 year and two months. 92 percent of blockchain projects simply fail [12]. Given the potential of the technology, this fact only justifies the need for further research. 
The objectives of this paper are to analyse the challenges that blockchain-enabled platforms face and provide recommendations on how to overcome these.

\section{LITERATURE REVIEW}

\section{A. Introduction: the Birth of Blockchain}

"Getting a global society to agree that something has value and can be used as a currency without government support and without a physical form is one of the most significant accomplishments in monetary history" $[6]$.

The Bitcoin white paper introduced a peer-to-peer electronic cash system [13] outlining the basic architecture of a public, distributed and immutable electronic ledger, better known as blockchain. Using cryptography and an innovative consensus mechanism called Proofof-Work (PoW), it allows for trustless and decentralised transactions. Blockchain technology, or simply blockchain, refers to the derivatives of Bitcoin's blockchain.

Blockchain is often described as a global, shared and distributed database [14]-[15] however unlike in traditional databases, records on the blockchain are immutable [16] and allow for users to retain the ownership of their assets. Blockchain was the first implementation of a new type of databases, commonly referred to as Distributed Ledger Technologies (DLTs), although most practitioners continue to use the original term, blockchain, and so will this paper.

A review of the existing literature follows in order to understand the current and future challenges faced by blockchain-enabled platforms from three perspectives: innovation, platforms and technology.

\section{B. Innovation Perspective}

\section{Blockchain as an Innovation}

"The technology most likely to change the next decade of business is not the social web, big data, the cloud, robotics, or even artificial intelligence. It's the blockchain, the technology behind digital currencies like bitcoin" [17].

The difficulty to define the type of innovation that blockchain represents stems from the fact that there are multiple and often contradicting perceptions about its potential (Fig. 1).

\section{Google blockchain is blockchain is the future blockchain is dead \\ Fig. 1. Contradictory perceptions of blockchain potential. Source: author based on Google search.}

Among those who indeed view it as innovative, two main groups stand out. The first conceives blockchain as a foundational technology [18] that enables social and economic progress, but not as a disruptive technology that could represent a threat for incumbents [19].

The second group advocates that blockchain is more than just a foundational technology to be used by incumbents: its decentralization potential is disruptive [20]-[22]. Coase's Theory of the Firm, despite dating from 1937, is particularly relevant in this context as it suggests that the economic system self-organises the distribution of resources with no need of central authority [23]-[24]. Certain firms' activities would therefore no longer be justified, considering blockchain's ability to reduce transaction costs and networking costs [8], [23], [25], [26]. For example, blockchain allows for instant and frictionless international payments seriously undermining existing brokerage functions.

Christensen's theory of disruptive innovation explores how startups can unseat established incumbents by offering products appealing to a low-end or new market that is often overlooked by incumbents, as these focused on satisfying most profitable segments. When challengers improve their offering and move to mainstream customers, incumbents face the so-called innovator's dilemma of competing with the challenger and risk to cannibalise profits from higher-priced models [27], [28]. Blockchain offers new value creation opportunities that were not economically viable until now. For example, blockchain applications for remittance services [1], an essential part for the financial inclusion of those unbanked, is a segment that until now had not been of interest to established financial institutions.

Nonetheless, it should be noted that disruption refers to a process that can take decades, explaining why incumbents often overlook the disrupters. The ability for blockchain startups to challenge incumbents will depend on their ability to move from inferior to high-quality services in the eyes of incumbents' mainstream customers [28].

\section{Blockchain Innovation Adoption}

The adoption of foundational technologies, such as internet and blockchain, often occurs in phases: single use, localised use, substitution and transformation [19]. A critical mass represents a tipping point at which the rate of adoption dramatically increases and reaches self-sustaining growth. At this point, growth is associated with the network effects that adopters exert reciprocally. Although the point of critical mass is unique for each technology, it is suggested to occur between ten to twenty percent of adoption [29]-[30].

Blockchain's potential to transform society is often compared to the disruption brought about by the internet [6], [17], [7]. The internet and blockchain share common characteristics: both are open, distributed systems and both innovations unlock new economic value by lowering the cost of connections in the case of internet or of transactions in the case of blockchain. Also, blockchain is considered a significant component of the web 3.0 [6], [1]. Some go as far as saying that blockchain is the embedded economic layer the web never had [7].

Despite the ambitious expectations to disrupt the financial system, bitcoin's volatility has prompted discussions about its intrinsic value [31] and raised concerns over its ability to store value [32]. Also, the rate of failure of blockchain projects, at an astonishing 92 percent [12], combined with the 90 percent value drop in 2018 of some cryptocurrencies, reflected a period of disinvestment and disenchantment [33]. Blockchain technologies are expected to overcome this Trough of Disillusionment phase by 2021 [34].

Dynamic processes of adoption, such as the Bass model, can be used to simulate scenarios and assess the effectiveness of certain strategies [35]. For example, in early stages of adoption, as it is the case for blockchain, advertising has a strong impact. As the number of adopters increases, advertising appears to be overshadowed by word-of-mouth, arguably due to social influence or network effects that represent a growth engine in the rate of adoption, independent from the actions of the firms.

Innovation adoption research covers well the factors that influence the rate of adoption and diffusion [36]. Among the factors for IT adoption, top management support appears to be a good predictor from an individual and organisational perspective. Other factors are technical experience, perceived usefulness, behavioural intention, external pressure, organisational size and the expected return on investment [30], [37]. Naturally, these factors are to be used with caution, as they often build upon the assumption that individuals are rational when evaluating the usefulness of the technology.

Overall, it took three decades for the internet to move through the four phases of adoption and reshape the economy. Given the lessons learned from the internet and the pace at which information is being shared today, the tipping point for mass adoption might be reached by 2025 [10]. 


\section{Platform Perspective}

\section{Strategy}

The transition from pipeline to platforms business requires three strategic shifts: from resource control to resource orchestration; from internal optimisation to external interaction; from a focus on customer value to a focus on ecosystem value [38]. Blockchain-enabled platforms strategies also call for a sense of community to create and capture value outside organisational boundaries [39]. However, a blockchain-enabled platform would have one main difference with traditional platforms: there is no central orchestrator.

Network growth and changes in the environment call for periodic revisions, as the difficulty to coordinate an ecosystem rises and with it the risks of failure. In this sense, strategy formulation should be conceived as an iterative process rather than a linear process [40]. Managers should avoid defining too narrowly the roles of participants and embrace creative agility to pursue new ideas, reflect and adjust [41].

Blockchain-enabled marketplaces are characterised by greater competition and lower barriers to entry and innovation, allowing network participants to co-create a shared infrastructure [25]. In traditional models of innovation, internal R\&D capabilities represented a competitive advantage and a key barrier to entry [42]. Interorganisational collaboration can benefit from spreading the costs and risks associated with intensive R\&D innovation projects. However, scholars suggest that firms have often missed the opportunity to use it as a source of competitive advantage. Companies have failed to achieve superior performance by focusing on outsourcing instead of building collaborative capabilities [43], [44].

Overall, blockchain-enabled platforms strategy is to be framed with a focus on networks rather than individual firms and should emphasise the co-creation of value [45]. In this sense, blockchain not only changes business models within corporations, it does so also at collaborative networks level [26].

\section{Business Models}

According to platform ecosystem strategies, building better business models is preferable than getting first to market [46]. Disruptive innovation theory also gives strategic importance to business models measuring the disruption phenomenon relative to the business model of another firm [27]. For example, Apple's mobile market domination is often associated with building a platform within a traditional pipeline business [38].

Disruptive innovation research provides useful recommendations for managers developing blockchain-enabled platforms [28]. On one side, disrupters are advised to focus on building business models highly differentiated from those of incumbents, rather than on building the right product. On the other side, incumbents facing disruption are encouraged to create new business lines designed to pursue the opportunities that arise from disruption. Last but not least, the incumbents' ability to manage and keep apart two different business units is argued to be critical for success [47].

The design and implementation of new business models while maintaining existing ones can be challenging for incumbents. As the disruptive theory advocates, the new offering can threaten the existing one and this can also occur for business models. Scholars have studied the benefits of ambidextrous organisations, characterised by higher degrees of agility and the ability to share a common vision and culture while maintaining separated explorative and exploitative units [48].

The ambidextrous approach [49] is conceived as a potential solution to the innovator's dilemma and a recipe for organisational adaptation and survival. In this context, senior managers appear again to be essential for a successful implementation, in particular: to articulate a common vision and a compelling strategy, to secure support from the management board and to manage inconsistencies or conflicts.

As suggested for the strategy, the appropriate business model should be flexible and scalable, following trial-error dynamics to accommodate for changes [50]. The lean startup approach, a term coined by Eric Ries [51], aims at optimising resources by using smaller and faster interactions for putting one's assumptions to the test with customers. The ability to integrate blockchain into existing workflows as well as the interoperability of platforms will prove critical to longterm scalability [52].

Among business models available in the literature, the business model Canvas allows for the development of alternative or radically new business models. In particular it can be applied to linear and nonlinear business models including platforms, facilitating the transition from pipeline to platform businesses, which is vital for incumbents [2], [53]. The business model Canvas can be used as a strategic management tool helping to capture, visualise, communicate and enhance both strategic discussions and idea generation [54], [55].

Empirical studies have also revealed that users are combining it with other methodologies such as: SWOT analysis, blue ocean strategy, lean startup and balanced scorecard [55]. One reason might be that the business model Canvas fails to capture key strategic factors for business platforms such as core value alignment, governance, trust, matching mechanisms or network effects [2], [26].

\section{Stakeholder Management}

Blockchain platforms and applications entail the collaboration of multiple actors at different layers of the architecture. The size of the network is perceived as a determinant factor increasing coordination complexity [19]. Individuals perform better when they feel accountable for their actions and believe their voices matter, reducing the risk of free riders. The combination of capabilities is a compelling argument to overestimate the potential for value creation and therefore performance expectations, while challenges are often diminished and "can seem like someone else's problem" [40].

Drawing a parallel with the known minimum viable product (MVP) introduced by the lean startups approach, a minimum viable ecosystem (MVE) would be conceived as the "smallest configuration of partners that can be brought together for a healthy minimum viable network that still creates unique commercial value" [56], [57]. By removing traditional hierarchical controls, studies reveal that an increase in commitment and responsibility for individual actions is commonplace. However, potential downsides of group dynamic such as pressure to reach consensus, fear of judgement or topic fixation can be intensified as control is less apparent but more intense [58]. Since group bias increases the risk of groupthink [59], the diversity of actors contributes to enriching the blockchain ecosystem.

The sustainability of collaborative networks depends also on the alignment of core-values and goals among members throughout the different phases of the platform. The design of collaborative networks core-value maps can facilitate the following: the selection of potential partners with aligned values, the identification of incompatibilities among members to support conflict resolution and the impact assessment of the addition of new members to the network [60].

"Successful innovation requires tracking your partners and potential adopters as closely as you track your own development process" [40].

Last but not least, uncertainty and asymmetry of information among contributors on a blockchain-enabled platform can alter individuals' perceptions and expectations. Misalignments in the ecosystem can lead to unintended adjustments and therefore a deviation from the strategy. The high interdependence of actors also implies that speed-to-market 
would be valuable only if partners are also ready, as bottlenecks may arise out of reach [40]. Managers are advised to assess the likelihood for parties to under-deliver, to understand the risk exposure and the underlying reasons -regulation, wrong expectations, incentives, lack of management support- and develop contingency plans.

\section{Governance}

Users interacting and transacting in traditional platforms, Uber or Airbnb for instance, rely on the platform owner's ability to set rules and processes to enable interactions in a safe environment. In blockchain-enabled platforms, trust relies on the underlying protocols like consensus mechanisms and the traceability of transactions. For the first time in history, users can reach consensus and coordination with no need for third-party intermediaries, allowing potentially for more granular and personalised services [8].

Trust and governance are therefore highly interlinked. Blockchain systems can be perceived as a form of governance, often referred to as decentralised autonomous organisations, a self-organised system as evoked with Coase's theory of the firm [23], 24]. These self-managed teams reach consensus about the platform's core values, design a shared mission and develop common practices. Governance and security deficiencies undermine users' perception of blockchain-enabled platforms' truthfulness and legitimacy [61]. Critical governance decisions have been around forks -"when someone takes the code of an existing application and uses it as the basis for a new application"- that created a competing structure and weakened the reinforcement effect resulting from the network effects of the original platform [62].

The governance should take into account the degree of complexity of the ecosystem [19] but also the degree of openness of the solution architecture [63], [8]. The latter would encourage both users and developers to contribute to the value creation. The main differences are as follows:

Permissionless networks are by definition uncensorable and therefore the governance could not provide sanctions, access or withdrawal rights. At the same time, as anyone can join the network and contribute, incentive mechanisms such as token rewards will have more importance to increase user engagement and avoid misbehaviour, excess or low quality of content that would destroy value.

Permissioned systems would benefit from appropriate levels of network coordination, control, compliance and human intervention. The governance of blockchain-enabled platforms in this case should contemplate the rules of functioning and provisions for dispute resolution, sanctions and access rights. Consortia formation offers advantages for managers as they are able to restrict the network to trusted nodes and members, however these less formalised relationships involve substantial trust-building, persuasion, shared vision and the alignment of expectations.

\section{Network Effects}

The consumer's utility associated to a product, physical or virtual, derives from its intrinsic value and the networked utility that results from the number of users in the network [64]. The literature recognises that network effects alter user behaviour and rationality [64], as the very nature of network systems reduces users' willingness to switch between platforms "unless everyone else does" [62]. This can also occur at the expense of adopting a superior technology. For example, the dominance of bitcoin reveals how competition from alternatives is not as effective due to the first mover advantage [30]. This reciprocal interdependence of users creates a reinforcement effect that was introduced in the adoption process.

The ability to bootstrap and operate a decentralised platform is referred to the cost of networking [25]. A native token is often used to crowdfund platform development and following that phase, incentive systems determine the conditions under which contributors are rewarded for providing resources such as computing power, applications or content. The cost of networking is therefore considered as an enabler for blockchain-enabled platforms to scale.

Although the customer base of incumbents' can be perceived as a deterrent, startups can benefit from a reduction in the cost of networking. Also, blockchain-enabled platforms can offer incentives for participants on the platform, by sharing the rewards resulting from direct and indirect network effects more fairly than in centralised platforms [25].

New blockchain-enabled platforms will have to face the chickenand-egg problem that is inherent in all platform businesses but also characteristic of immature markets such as cryptocurrencies [62]. This chicken-and-egg scenario brings a new type of network effects where tokens have the potential to overcome the bootstrap problem, offering a greater financial utility for early adopters when the application utility is lower [65].

The literature suggests that managers willing to assess the value of a blockchain-enabled platform over time can rely on Metcalfe's Law, which states that the number of users in the network is measured by the number of unique addresses participating actively [66]. In this sense, Metcalfe's Law defends that the utility value of the network is proportional to the square of the number of users of the system.

Metcalfe's Law has served to diagnose bubbles and crashes in bitcoin [67]. These bubbles resulted from unsustainable, greater than exponential growth, leading to a correction of the value. Temporary value bubbles occur when the value of the network is not justified with a particular development that increases the value of the network, or an accompanied growth in the number of users participating in the network [66].

Because digital networks give rise to similar network effects as those traditionally associated with physical networks [68], one could expect a winner-takes-all dynamic [69], [70]. However, since participants' contribution on a blockchain-enabled platform is proportional to their stake in the platform, minorities that disagree with a suggested change face low lock-in and can be incentivised to fork at any time to create a separate platform [25]. The network split however questions the ability for platforms to scale, converge and ultimately experience a winnertakes-all dynamic.

Overall, managers are advised to focus first on the value of the interactions and assess the nature of network effects the platform is subject to [70]. Particularly in the context of blockchain-enabled platforms, managers need to find ways to ensure that the openness is translated into sources of value creation, rather than creating noise that would hinder user interaction [38].

\section{Technological Perspective}

\section{Blockchain Architecture}

Blockchain is conceptualised as a multi-layer communication and storage system [71], [72]. Important characteristics are: first, these layers are interdependent as participants acting and deciding at any of these layers are influenced by the decisions taken in the underlying layers; second, blockchain runs on top of internet, and is hence completely dependent upon the security of the latter.

There are multiple actors involved on a blockchain-enabled platform: architects to design the platform, developers to create applications and smart contracts, network operators, blockchain regulators and users. The challenge stems from the fact that, unlike in other IT architectures, actors in the system do not necessarily know or trust each other, yet they all contribute to the network in exchange for value [73]. 
Different blockchains result from the different approaches to access rights, consensus mechanisms to record creation and validation, and incentive mechanisms [22], [72], [74]. Despite a lack of consensus in the literature, blockchains tend to differ based on choices made across two dimensions:

\section{- First dimension: access}

- Permissionless blockchains, such as Bitcoin or Ethereum, allow anyone to join the network, create a record and act as a verifier. However, these blockchains suffer from low throughput, scaling limitations and high energy consumption.

- On the other hand, permissioned blockchains require the authorisation from designated parties to be able to create a record and transact; whether a consortium, such as R3 Corda, or a unique entity, this is a compromise to the decentralization promise of blockchain.

\section{- Second dimension: transparency}

- Public blockchains allow anybody to access the information and participate pseudonymously.

- Private blockchains allow data to be shared only with trusted parties and offer better privacy.

Whilst permissionless blockchains are often associated with public, and permissioned associated with private [26], there are use-cases for all four combinations. Examples of public permissioned blockchains can be found in supply chains, or in annual corporate reports where only legitimate participants can add information, but everyone can access it.

Further to that, the technology imposes some trade-offs known as the scalability trilemma where blockchain systems can have at the most two out of the three following properties simultaneously: scalability, security and decentralisation [75]. Blockchain developers can navigate among these trade-offs to personalise the blockchain solution, leading to multiple possible combinations of hybrid blockchains [76]. These hybrid systems have emerged to respond to often conflicting requirements and balance the existing trade-offs [72], [77]. For example, applications in the financial services demand a high level of transparency for reporting and regulatory reasons whilst requiring strong guarantees on the privacy of their customers' data.

\section{Blockchain Applications}

Blockchain in particular and DLTs in general have received great attention from the "tech" community, industry practitioners, scholars, policymakers and the media. Although over promotion can be counterproductive for the long-term development of a new technology [78], the number of blockchain applications is growing at pace [79]. There are many potential use-cases beyond traditional financial transactions such as digital identity, voting systems, supply chain, personal data monetisation and remittance services [80], [20].

Although it remains difficult to predict what use-cases will have a lasting impact, and if and where they will converge, the development of blockchain since 2008 can be split in four phases [7], [81]:

- Phase 1: focus on economic efficiency and costs savings for decentralised transactions of currencies. This phase saw an explosion in the number of cryptocurrencies created and traded.

- Phase 2: 2015 saw the release of Ethereum, a turing-complete distributed public blockchain network that offered for the first time the ability to create fully functional smart contracts. Smart contracts are computer code that can technically enforce a contract between multiple parties, without the need to trust the parties nor a trust broker [82]. The Hyperledger foundation followed to offer blockchain solutions for enterprises with a series of frameworks and tools. This second stage explores decentralisation beyond financial markets and the transfer of digital assets beyond cryptocurrencies.

- Phase 3: focus on the development of decentralised applications, and in parallel, research on how blockchain can reduce organisational boundaries and provide fairer transnational governance structures to generate greater value.

- Phase 4: the intersection of blockchain and other technologies such as artificial intelligence (AI) and internet of things (IoT).

Paradoxically, the fact that the community is structured around the idea of decentralization, makes it incredibly difficult to pursue, and hence reach, any form of consensus on taxonomies, let alone standards. This is probably the main obstacle to the democratisation of the technology at this stage, as it was for Internet in the 80s [83].

Overall, the literature reveals that the diversity of applications for blockchain explains the diversity of opinions about the value and potential of the technology. In this sense, no one solution fits all. The theories of adoption and diffusion suggest that adoption occurs in phases that can be fostered or hindered by multiple factors. The pace of evolution and associated uncertainty around blockchain require a continuous adaptation of the strategy of blockchain-enabled platforms to changes in the environment. One important takeaway is that companies building collaborative capabilities can and should use these as a source of competitive advantage. Also, platform managers willing to embrace the technology and rely on existing business models, can turn to the business model Canvas. Last but not least, the literature review revealed the lack of a framework to guide those building blockchain-enabled platforms.

\section{E. Research Focus}

The hype around blockchain, stemming mostly from its promises of global disruption, has resulted in more than half a million new publications between 2016 and 2018 [74], from white papers to blog articles and semi-scientific contributions. Scholars have only begun to look at blockchain and so far, mainly focussed on three themes: demystifying the technology, its disruptive potential and identifying specific use-cases [19].

However there remains many open questions for incumbents and startups willing to embrace blockchain technology. The high rate of failure of blockchain projects is indicative of a real struggle to leverage the technology for commercial success. There is a need for research on the main challenges blockchain-enabled platforms are facing today and how these challenges differ for incumbents and startups. This is the focus of this paper.

\section{Methodology}

\section{A. Research Strategy}

The empirical research in this paper focuses on the challenges that blockchain-enabled platforms currently face. While a case study strategy would offer valuable insights, it would fail to provide a holistic view of the challenges faced by stakeholders, given their diversity and given the divergent nature of the technology.

A survey strategy [84] was employed for the purpose of this research because it yields extensive and detailed information to interpret and draw representative results about the population. Given the limited empirical work available, the author of this paper followed an inductive approach with a multi-level design to reveal the challenges at the platform-level as well as the dependencies at inter-players levels [85].

\section{B. Data Sources}

The sources for data collection used are threefold: first, in-depth semi-structured interviews; second, emails, observations and follow- 
up interviews; third, internet resources. The triangulation of data from various sources strengthened the robustness of the findings [86], [87].

Acknowledging the limitations of closed-ended questions, characteristic of questionnaires, the author opted for in-depth semistructured interviews [88]. This type of qualitative research allowed to unveil the root causes of the research question and provided for flexibility to formulate further questions that would explore specific themes based on the experience of the informant [84], [85].

\section{Data Collection}

Considering that the researcher had no personal ties with the informants, studies confirmed the effectiveness of introductory messages and field conferences [89]. In this sense, the author of this paper approached leading actors through LinkedIn explaining the objective of the research and why the experience of the informant was relevant. Furthermore, blockchain and fintech conferences proved to be the ideal setting to network and collect data through observations where leading actors discussed the potential and challenges of the technology.

Following a multi-stakeholder approach, twenty semi-structured field interviews were conducted with leaders in blockchain and platform strategy, taking into account ethical and privacy considerations [88]. A summary of the informants' profile, gender and geography can be found in appendix A. The diversity of the group aimed at providing a comprehensive overview. All interviews were conducted through web conferencing, video or call, an environment conducive to productive discussions without interruptions. On average, interviews were an hour long, ranging from forty to ninety minutes.

\section{Data Analysis}

The twenty interviews were recorded and transcribed. As suggested for inductive analysis, the information collected was organised, disaggregated into categories making use of mind maps and tables in order to highlight patterns and differences among the different interviewees [90]. Also, the comparison with the existing literature allowed to uncover similarities and differences, demonstrating the need for further research.

\section{FINDINGS}

This section sets out the findings from the twenty interviews conducted with leading blockchain-enabled platform actors. As with the literature review, the findings have been analysed from three standpoints: innovation, platforms and technology. The interviews allowed for the identification of nine main challenges that blockchainenabled platforms are currently facing.

\section{A. Innovation Perspective}

- Challenge 1: the innovation potential of blockchain is debated.

In innovating with blockchain, incumbents and startups mostly pursue different objectives, respectively efficiency and disruption. Consultants and entrepreneurs agree that large organisations face difficulties to understand what blockchain is and think about it in innovative terms. There are multiple reasons for that. First, the centralised nature of the business makes it difficult for senior managers and executives to think decentralised. Second, large organisations tend to prioritize improvements in efficiency over risky innovative paths: in most incumbents, under-resourced IT departments have little time to explore new ways to do their job, let alone to do business. A blockchain service provider explains: "What limits large organisations is that they are stuck in the traditional way of doing business".

As a result, most incumbents deny the disruptive potential of the technology and recognise that their investment, if any, is mainly for efficiency purposes. Paradoxically, the very same executives argued that embracing new technologies such as blockchain is a necessary step for survival. Furthermore, incumbents tended to praise their own innovation efforts, legitimizing their investments with long-term positive spillovers. A financial executive said of the innovation efforts of his company: "We are innovating like crazy and the other great news is that because we already have the network, we can roll it out and make it backward compatible. I am really looking at cross-border payments in our banking community for another 100 years of resilient and good experience for customers".

Startups, on the other side, tended to focus on finding new ways to create and capture value; much enthusiasm was shared, for instance, around the potential for blockchain to unlock the data economy, the access economy and ultimately the circular economy. An entrepreneur explains: "I think we are moving into a new world war, and while we all know it will be fought on the internet, few realise the reason for the war will be the internet of value". Blockchain, they argue, could for instance provide users ownership over their data and eventually remuneration for its use.

The fact that incumbents and startups fail to agree on the disruptive nature of blockchain is a challenge for it limits cooperation, fosters fragmentation and ultimately hinders innovation. The risk for entrepreneurs is to fail to gain sufficient market share, whilst the risk for incumbents is to miss the train and find themselves two or three innovation waves behind, at which point they will no longer be able to catch up.

- Challenge 2: the mass adoption of blockchain-enabled platforms is constrained by endogenous challenges such as crypto volatility and digital divide.

Experts agree that the cryptocurrency market is perceived as an indicator of the health of the whole ecosystem that leverages blockchain, and the volatility of cryptocurrencies negatively affects the adoption of blockchain-enabled platforms. The hype around cryptocurrencies in 2016-2017 attracted speculators, who further increased price volatility, creating a speculative bubble. The 2018 crypto market downturn balanced the type of participants in the ecosystem. The ability for investors, users, enterprises and governments to use and accept cryptocurrencies as a method of payment is seriously undermined by the high volatility of prices. Furthermore, mass adoption is constrained by the fact that cryptocurrencies still cannot really be used as a mainstream method of payment. This situation creates a vicious circle where a low market acceptance of cryptocurrencies is translated into low market liquidity. An entrepreneur explains how tokenization can have a positive spillover increasing liquidity within the ecosystem: "For our project to scale and be successful we required liquidity, the one benefit from doing it with tokens is that it becomes accessible to a lot of people, and people can exchange and can keep it, hold the token or not".

From a user perspective, price instability impacts buyers' purchasing power and behaviour. From an enterprise perspective, volatility hampers businesses' ability to predict revenues and invest accordingly. Even blockchain entrepreneurs who raised capital through Initial Coin Offerings (ICOs), saw much of their capital "burnt" by the market itself. Volatility damages investors' confidence and hinders long-term decentralised applications that require price stability. As an entrepreneur warns, "Cryptos are considered the most dangerous investments and it is not a surprise that regulators are trying to protect investors. Hopefully cryptos will stabilise, otherwise there will be huge problems for mass adoption".

While blockchain-enabled platforms are becoming more common, they are still for "tech-savvies". Experts recognise that despite the increase in adoption since 2016, the diversity of users in blockchain- 
enabled platforms remains the same: users are individuals that are fairly familiar with cryptocurrencies and have a particular interest in decentralisation. As an entrepreneur describes, "we haven't really seen normal users, almost everyone that uses the platform, understands what Bitcoin is".

From an end-user perspective, experts argue that crypto-illiteracy would be a barrier for adoption, and so advise that the emphasis should be placed on the advantages the technology offers such as traceability, transparency and immutability. An entrepreneur explains: "What we want is to sell our solution without talking about blockchain, our customers mostly don't care about using blockchain or not. We don't want to scare people by using some scary words, such as cryptocurrencies or blockchain".

From a business perspective, experts highlighted the difficulty to understand blockchain and to develop sound use-cases to what consultants and Blockchain-as-a-Service (BaaS) appear to be essential. These organisations have multidisciplinary teams that provide support for startups and large organisations at different levels: requirements drafting, strategy definition, blockchain development, and last, training and maintenance.

- Challenge 3: the mass adoption of blockchain-enabled platforms is constrained by exogenous challenges such as regulatory divergence and access to vital financial services.

Blockchain-enabled platforms are constrained by divergent and sometimes conflicting regulatory approaches. A barrier for platforms in terms of development and liability is that in some regions, platforms are not able to operate due to regulatory uncertainty. A risk arises for platforms when users circumvent national regulations in place. In response to the legal vacuum, crypto-friendly countries such as Switzerland, Malta and Liechtenstein, have tried to attract crypto and blockchain businesses. These countries have adapted state policies to increase transparency and regulate the activities in the blockchain and crypto markets. However, the practical implementation of regulation adds more complexity for blockchain-enabled platforms as it is bound by national jurisdictions while blockchain is a global phenomenon. A legal expert explains: "The ICO guidelines provide a small framework but then [regulators] said that the existing laws can be applied to blockchain. The real dilemma is how to synchronise the existing legal framework with a brand new technology and bring both together to build something".

Another key external difficulty for startups building blockchainenabled platforms is access to critical financial services. Some blockchain entrepreneurs have agonised as banks have repeatedly rejected to support their projects. Part of the reason banks are giving crypto startups a hard time is the difficulty to comply with heavy regulation, from tracking the origin of the funds raised, to taxing profits, or lending given the high-risk profile of crypto markets. An entrepreneur explains: "Banks don't want to get involved for fear that there is money laundering going on in crypto, the amount of work they would have to do to ensure a client's money is clean outweighs what they would earn in fees".

Businesses, particularly in the financial sector, have fiduciary duties and responsibilities. Complying with "Know Your Customer" (KYC) and "Anti-Money Laundering" (AML) procedures is a challenge for businesses as these are not embedded in the blockchain. With that being said, a bank executive explains how the dilemma is not with the technology: "It is not a blockchain problem, the issue is that the projects themselves need to comply with the regulation. This can be solved by making whitelists of investors that comply with KYC/ $A M L$ procedures. There are companies that are doing this very well".

Even entrepreneurs who managed to raise capital without using traditional markets, through ICOs, faced difficulties. Those that did survive the crash of the crypto market interestingly face legitimacy issues, as explained by an entrepreneur: "ICO booming in 2017 brought a lot of attention, notably bad attention, as it is now estimated that at least $80 \%$ of ICOs in 2017 were scams and failed to deliver on their promises. Since we have raised this huge amount of money at the very specific time where there were so many scams, so many bad projects, we kind of had to prove that we were not a scam ourselves".

\section{B. Platform Perspective}

- Challenge 4: misguided and misguiding managers lead many platforms to fail.

This challenge is both a platform and a technological one. For most entrepreneurs interviewed, the decision to develop a blockchain platform has been influenced primarily by curiosity and experimentation, less so by a clear view on the returns. Larger businesses also struggle with a similar challenge, shareholders or the executive team asking senior managers to develop a platform based on a technology they barely understand. A consultant explains: "Senior executives did not have the time to learn or understand what blockchain is and is not, often pressed by the engineering departments who would put more emphasis on the technology than the returns for the company".

Platforms and blockchain are considered still buzzwords. As a result, both remain misunderstood by most people, hampering their ability to properly evaluate the technology requirements for specific platform use-cases. The high level of interest for platforms and blockchain technology lure enthusiasts and enterprises into the trap of defining a solution before the problem. As a blockchain consultant puts it: "the biggest challenge for enterprises is to find their way into blockchain and into platforms, because they don't know what kind of problems these can solve today. For still too many people, the sole purpose of building a blockchain platform is to tell the world you are using blockchain".

Choosing the right blockchain technology stack for the right platform requires a thorough case-by-case assessment of the requirements. The fact that end-users and businesses often have opposite requirements when it comes to blockchain-enabled platforms, is a serious challenge for developers if they are not clear on what problem they want to solve. Experts interviewed recognised they had too often considered the requirements from the wrong perspective.

Not surprisingly, consultants confessed that most of the time, proof-of-concepts revealed that blockchain was actually not the optimal solution and that other technologies could solve the problem at hand better, faster, and for a fraction of the investment.

The hype around blockchain leads many to try to solve the big problems before the little ones. Finding the appropriate size and scope of a platform to solve a particular problem can be challenging. Bitcoin has proven that blockchain is a global network that can scale up from a business functionality point of view, yet it has also proved that it is far from being able to compete today with existing payments systems. In that sense, experts agreed that at this early stage, a global and large platform is a mistake and recommend to start small.

Another consultant emphasises the importance of speed-to-market: "If you have a problem, validate it, build something with it and release it in less than three months and if you can't do that it means that you have to narrow down the view to something very specific until you are confident you can build it in three months". This is linked to challenge 8 hereafter: as time-to-market is shrunk, security becomes a second priority whilst it is paramount to trust, and trust is itself paramount to blockchain users.

- Challenge 5: blockchain-enabled platforms face new and unique governance issues.

Conflicts of interest can quickly arise in blockchain-enabled 
ecosystems. A profit-oriented platform, leveraging on blockchain or not, often has a set of obligations towards its investors such as dividends and governing or voting rights. Although during the early stages of adoption, the interests of the users are generally aligned with those of the platform, as the network grows and captures more value, the need for maximising the financial returns for shareholders prevails. This scenario does not necessarily translate for blockchainenabled platforms. A blockchain entrepreneur of a fully decentralised blockchain-enabled marketplace explains why he wants to separate the foundation in charge of the platform from the company that initiated the development of the project: "We want to split the foundation and the company because the company is very incentivised to not decentralise whereas the foundation's goal is to make sure that the protocol succeeds. We are trying to separate those concerns; we have a lot of those discussions internally if we want to make money or not. And that shouldn't be a decision we make. So, I think that we just want to get away from that. From a company perspective, it doesn't make much sense, but we want to succeed whether the company does or not".

Interestingly, another entrepreneur explains how he managed to keep his community together by leveraging a utility token sale that allowed investors to participate in the network and at the same time redistribute value equitably among the different actors: "those that invested during the ICO, we call them "our" community and not shareholders as we don't owe them anything, legally speaking. They have bought the product we are working on to be released. We have a very transparent way of communicating our advancements and what the money is used for".

For incumbents, the shift from "ego-systems" to ecosystems will take time. Large organisations are having difficulties moving from a silo perspective to a multi-stakeholder perspective as they often have their own expectations of what the solution should look like. Moreover, participants in a blockchain network are often required to wear many hats as they can have different roles in different platforms and a separate mandate within their own organisation. A key challenge is how different parties or even competitors can work together to build an ecosystem and align their objectives and core values for a specific purpose.

Within a blockchain ecosystem, collaboration aims at creating and enriching the network while these parties might compete at the application level. Although a founder would set up the first node to start a network, in a distributed model there is no central ownership of the platform. In this sense, participants on the network need to collaborate around the design, governance and monitoring of the platform. The community model of management relies on the wisdom of participants on the platform to make the right decisions to make the network secure, stable, resilient and accessible. A platform expert explains: "we call it Platform 2.0, the combination of blockchain and AI to do cognition at scale, or so-called collective intelligence, to be able to jointly address global challenges". For the time being though, for blockchain-enabled platforms to scale, governance will need to rely on more than participants' wisdom or AI.

Directly linked to the governance model is the size and composition of the ecosystem, and there is little guidance available on the topic. The challenge is to decide with who to build the platform and whether it is pertinent to maintain some kind of privileges or superiority for the work already conducted, as it may disincentive other partners to join the network and undermine the benefits of blockchain.

All these difficulties converge into one of the most difficult challenges for blockchain-enabled platforms: decentralized governance. Governance, in the case of blockchain, encompasses the definition of rules and norms that determine the access rights, transaction validity, conflict resolution, issuance of new assets and tokenization. The agreed governance is implemented on-chain, hardcoded for instance in consensus algorithms that are aimed to be self-governed. Nevertheless, governance also occurs off-chain. Even permissionless blockchains such as Ethereum rely on an off-chain governance process for a variety of decisions such as proposals for additional features. Examples of off-chain channels are the Ethereum Github webpage or the Ethereum Community Forum. On-chain processes require the validation from stakeholders; off-chain processes may not. Managing these processes in parallel, in a fully decentralized manner, is proving to be a major obstacle to the growth of blockchain-enabled platforms.

Blockchain experts mostly agree that defining governance models should precede technological choices as the latter implement the rules and internal processes agreed upon. Surprisingly though, multiple experts interviewed confessed they had not yet a clear view on governance, rules and conflict resolution. In two cases, governance was delegated to a community of volunteers. An entrepreneur that launched a platform two years ago argued: "The things that we are focusing on right now are outside of the governance process. Governance process in decentralised apps is quite new for us and we haven't decided yet how it will be structured. Right now, we are putting together a foundation board, people that we know are coming from different areas and that would serve as a fair and diverse community". Indeed, as the off-chain governance process can prove to be challenging, particularly in public networks, it is often delegated to foundations or communities of volunteers.

"It's been 4 years and we are still trying to solve the same problems that we thought of when we started. It is really hard, not just the technology but the way people act it is different from centralised networks and it is very hard to police them. So getting people to do the right thing is hard", concludes an entrepreneur.

- Challenge 6: incentives strategies and mechanisms for the launch, development and operation of blockchain-enabled platforms are still exploratory.

The economic framework of any ecosystem takes into account the different motives of participants. As highlighted before, these may differ within and across blockchain-enabled ecosystems. In permissionless networks in particular, economic incentives are fundamental as these networks rely greatly on the contribution of users to the value generated within the network. Tokenization is one of the ways in which blockchain is disrupting traditional businesses: crypto-tokens are a digital form of value that allow incentives to be kept aligned between network participants and foster network growth. Although tokens were previously used mostly to raise funds in ICOs, most tokenization is expected in supply chain, loyalty programs and membership rights.

The challenge is how to incentivise participants and ensure that the creation of value is maximised and the destruction of value minimised. There is not one model fits all, notably given that different platforms have different stakeholders, like curators and moderators. Their role is essential for blockchain-enabled marketplaces to compete with giants like Amazon on the relevance of their listings per customer. An entrepreneur shares concerns about the potential spillover effects of growth in self-governed organisations: "Right now it is very basic, you just take whoever but I think that if it gets to millions of users it would be hard to decide who you wanna use as a moderator. Moderators that are more responsive, more trustworthy, with better reputation may become expensive".

An important component to incentivising stakeholders to join one's platform is communication. The hype around blockchain technology led to the publication of hundreds of ambitious blockchain-platform white papers, well supported by marketing plans and little more. Whilst these projects did capture enough attention to raise capital through ICOs, the majority failed to deliver tangible results let alone returns for 
initial backers. Experts criticised that many startups often rush out the process of ideation, formation and implementation when they fear they run out of cash. An entrepreneur explains: "One of the first mistakes that startups make when they get funded is to over-recruit, purchase infrastructure, travel everywhere and all the sudden there is nothing left to develop the product".

One last challenge concerning incentivising users to join a platform is community support. Projects with greater decentralisation characteristics resonate better with the intrinsic motivators of blockchain evangelists and other "crypto-lovers", who in turn voluntarily support the projects on social media, in conferences and in community forums. Despite the lack of a well-defined strategy, these platforms appear to grow organically, relying on the power of word-of-mouth. The founder of a public permissionless blockchain-enabled platform confessed: "We never did any formal marketing or advertising efforts until the last few months other than just us tweeting. The way that we built it up was to focus on getting developers to build the platform but kept on engaging with people within the crypto community to continue inviting people to join the project. I think that because the idea was kind of crazy, we got a lot of trust early on which brought a lot of attention to what we were doing".

The challenge is that the opposite is also true, and these actors often badmouth projects they disagree with, ultimately undermining their ability to raise capital or develop their customer base.

\section{Technological Perspective}

- Challenge 7: the skills required to develop blockchain-enabled platforms are diverse, scarce, and under stress.

Blockchain is still in its infancy. This implies first a shortage of blockchain developers in the world. Although today, large organisations often have their own innovation labs, the skills shortage makes it close to impossible to find, never mind hire, experienced blockchain developers. It is also worth noting that this is further exacerbated by the fact that the financial sector, one of the first in attracting these skills, has the means to retain talent. An entrepreneur explains: "Finding people to write and test the code can be very expensive. They are expensive because they are only a few. Many experts who used to work for leading blockchain companies have been poached by banks".

Interestingly though, this lack of competence is fostering collaboration between BaaS companies, consultant services, startups and established organisations. The Enterprise Ethereum Alliance or the $\mathrm{PwC}$ and Microsoft alliances are notable examples.

Startups recognise that developers' motivators are not only extrinsic, notably financial, but also very much intrinsic. Blockchain remains one of these fields that attracts people pursuing other objectives, like technological breakthroughs, social or political impact. Attracting talent in such a competitive market is then even harder, as recruits, often millennials, look for cultural fit and social impact, not only for an attractive benefits package [91]. Last, given the volatility of the market and the disruptive potential of many projects, it is particularly difficult to retain talent as stock options may suddenly drop in value and competitors develop more appealing projects. The fact that blockchain is still in its infancy also implies that the technology is new, and changes often. As a result, blockchain developers spend time solving technical bugs without much experience doing so. A developer describes how challenging it is to stay up-to-date: "I hope that we will not see more divergence because it is hard to find the proper technology in this kind of context. When we are developing a blockchain application we know that maybe in one or two years we will have to recode everything using the latest version because the way we coded will be obsolete. We are aware of that and we are taking the risk".

- Challenge 8: the security implications of blockchain are largely overlooked.

Experts tend to agree that successful blockchain-enabled platform development is bound to follow an iterative process: first, prototypes should be built as quickly as possible using minimum resources; second, potential customers should test prototypes and their feedback be used to improve the solution; third, the process should be repeated over and over again.

This poses a critical challenge, all the more important because it was not mentioned by any of the interviewees. The security of blockchain was never discussed yet it is of tremendous importance for ledgers are immutable, smart contract code is law, and the transparency of public blockchains makes its data accessible to all, including hackers. Security-by-design, or even better, security-by-default, is a growing concern and hence discipline in other emerging technologies such as $5 \mathrm{G}$, IoT and AI. Indeed, many stakeholders worry that future mobile networks can be spied upon, that IoT devices may be hijacked or that AI will turn against humans... Yet all these technologies can be updated when a vulnerability is discovered. Not blockchain, at least not without a hard fork, which impacts trust considerably.

Unfortunately, too few worry about the security implications of sensitive data being stored on the blockchain, misuse of legitimate protocols to create money out of thin air, etc. As a result, blockchain security vulnerabilities have already led to significant loss of value, and bad press overall for the entire community.

Last but not least, the combined skills shortage in cybersecurity and blockchain is a serious growth barrier for the technology [92].

- Challenge 9: blockchain technology may not be ready yet to deliver fully on its key promise: decentralization.

For blockchain to become a unifying system to record all transactions, there are still many obstacles: today, information is managed in silos within organisations and often duplicated over and over again. The reconciliation of information across systems is timeconsuming and error-prone. Blockchain is an enabling technology and the quality of the information it will provide will be as good as the data source. Thereupon, blockchain-enabled platforms' ability to scale up to full adoption is dependent on the ability for platforms to interoperate between themselves and with existing information systems. A digital transformation executive explains: "blockchain needs to operate over homogeneous datasets. The challenge is that information systems have evolved independently with different standards. Even information systems using the same language are not managed homogeneously. Blockchain requires that these different datasets are coordinated so that they can connect to each other and understand each other. The challenge is how to turn heterogeneous databases into homogenous ones and make them compatible to exchange value".

Today, the return on investment (ROI) to migrate existing systems and processes to blockchain-enabled platforms fails to convince incumbents. Even after running several prototypes, for most, the perceived ROI was uncertain and rather long-term, notably because it is directly dependent upon the ability or commitment of other participants in the network to invest as well, so information can be exchanged. Experts interviewed argued that none of the available options today scaled enough to convince investors and the broader ecosystem. As an incumbent explained: "Based on our experience so far, banks are not ready to implement blockchain as they would have to migrate and be interoperating with that new platform. For them it is much easier to implement it with APIs and our existing offer than it is with blockchain".

For decentralization to become mainstream, blockchain-enabled platforms may require centralised implementations first.

Incumbents focus primarily on performance, privacy, scalability and the ability to transact only with interested parties. In that sense, the 
additional complexity and costs associated with creating "artificial" permissions on top of a permissionless platform outweigh the benefits. As a result, most incumbents are developing solutions on private and permissioned blockchains and often using IBM's Hyperledger or Corda. An incumbent executive explains: "Hyperledger of course. We use smart contracts to execute payments' instructions. The buyer, the seller and the involved banks are able to transact ensuring that only the parties involved in the transaction have access to the details. You can't do that easily with Ethereum".

Naturally, on the other side, many startups hope to leverage decentralization to grow and challenge incumbents in no time. Their B2C applications try to benefit from the higher degree of security, anonymity, transparency and decentralisation of public and permissionless blockchains. And Hyperledger is obviously not the solution of choice, as explained by a consultant: "Hyperledger, to my perspective, is too proprietary even though it is open source. If you think about the clients that do implement Hyperledger today, these are all premium IBM passengers".

There is a new generation of platforms bringing together private and permissioned with public and permissionless platforms. Kaleido, for instance, is a full-stack enterprise platform developed by ConsenSys that records only part of the information on the main chain of the public blockchain. In this sense, Kaleido offers developers the flexibility to select the most appropriate protocol to build on top of Ethereum and uses AWS infrastructure to scale up. The sidechain allows for greater levels of privacy and speed to test a new application. However, here again, there are contradictory opinions as an entrepreneur explains: "for enterprises, blockchain is generally just a technology enabler while for some end-users, it is almost a religion. Balancing expectations is difficult: running decentralized blockchain applications on the most proprietary and biggest cloud on the planet can prove challenging from an end-user perspective even if it can make perfect sense from a business perspective".

Overall, the fast evolution of blockchain technology calls for agility. The ability to stay at the forefront of technological developments will depend as much on the collaborative capabilities among stakeholders as on the ability to go to market with fast-built prototypes and improve the solution on a continuous basis. Currently, it appears that centralisation may be a necessary step to take for the technology to converge and gain adopters. Migration and interoperability costs are currently perceived as major obstacles and regulation and standardisation have not really kicked in yet. If and when these barriers are lifted, the technology will face its ultimate challenge: shifting fully towards decentralization.

\section{Discussion}

The literature review and the diversity of profiles interviewed provided a qualitative basis for a holistic analysis of the key challenges inherent to blockchain-enabled platforms. This analysis, in turn, provides the basis for the following discussion, structured around two sections: first, a comparative analysis of the findings and the literature review; second, a set of recommendations for managers developing blockchain-enabled platforms. Also, a graphical abstract a theoretical framework capturing the key takeaways of this paper can be found in appendix B.

\section{A. Comparative Analysis}

Traditional centralised authorities are seeing their legitimacy increasingly questioned as blockchain technology matures. Libertarian blockchain evangelists praise the trustless and apolitical nature of blockchain technology, pushing to replace hierarchal centralised systems, reduce market power, privacy risks, censorship risks and give back ownership of data to their owners [62], [25], [16]. Yet as the findings unveiled, there are multiple and interrelated challenges that hamper this vision.

The findings confirmed what the literature suggested: there are divergent opinions on the disruptive potential of the technology. Some experts interviewed look at blockchain to improve existing processes, while others pursue much more ambitious goals, such as the internet of value. The disruptive innovation theory in the literature review also showed that startups can supplant incumbents by targeting new markets that remained ignored by the latter: given that blockchain is still in its infancy, no finding confirms this theory yet.

Findings also support the fact that adoption drivers differ between startups and incumbents. While the former are often looking into new business models, the latter are mainly embracing the technology for efficiency purposes, without questioning existing business models. In particular, incumbents often casted doubts on the ROI, given migration costs and uncertain returns. That being said, the findings also revealed that some large organisations, particularly in the financial sector, are actually looking at blockchain in great depth and have gone as far as insourcing their blockchain development efforts entirely.

Despite transparency and community support being prominent aspects in the blockchain space, the literature on decentralised governance is limited and part of the reason is the difficulty to capture and share lessons learnt [93], [94]. Experts also recognise that there are no successful examples with sufficient track record as of now. The findings revealed that for important decisions such as the development of additional features, governance in public blockchain-enabled platforms often occurs off-chain [95]. As these transactions do not occur on the main blockchain, the latter loses some of its core values points such as transparency. It remains to be seen how data exchanged off-chain will be managed and taken advantage of.

The literature reflected well the need for a lean startup approach [51] which emphasises the need for a MVP. However, the fast pace of change and the inherent trade-offs that the technology imposes, calls for temporary concessions, the findings revealed. It appeared that managers are accepting the introduction of centralised components for the sake of adoption, even on the essence of blockchain: decentralization.

Blockchain was designed to replace imposed confidence, or vertical trust, by voluntary confidence. Whether this happens or not, a transition period is needed to replace the existing trust models, notably on companies and processes. The findings revealed how many of these companies shy away for a variety of legitimate and questionable reasons. For instance, if the current volatility of cryptocurrencies is indeed an obstacle, price fluctuations will eventually stabilise as they did for tulips or gold [96], when more people get involved and liquidity increases. As a result, this argument is short-term at best, and does not affect the long-term potential of blockchain. Not recognising this potential is as much a risk as it is to invest in crypto-markets today.

The literature review also suggested that regulated institutions and established organisations would try to circumvent blockchain businesses to protect the status quo [6]. The findings indeed revealed that they do play a role in dismissing blockchain, discrediting the legitimacy of blockchain businesses. Although the first adopters were often associated with illegitimate activities, the Bitcoin economy has grown in size and scope with legitimate applications [97].

Also, the findings illustrate challenges that were not captured by the literature review. First, blockchain-enabled platforms often need to navigate uncharted regulatory waters for the service they pretend to offer, but also go to great lengths to secure basic but vital financial services for their very own corporate operations, from raising capital to paying salaries [98]. On the other side, the findings revealed that many blockchain projects with ambitious marketing plans were unable to control their expenses and quickly ran out of money. 
Among the factors of adoption that the literature review highlighted, the findings revealed that external pressure and management support do not always lead to positive outcomes as managers of blockchainenabled platforms also often rushed into development without a proper use-case assessment.

In this light and despite what libertarians may think, it seems that mass blockchain adoption is going to require top-down initiatives, even if only for a few years, to complement bottom-up work. This does not mean that bottom-initiatives play no role, to the contrary. Among adoption strategies, the literature review suggested that advertising would be more efficient during the early stages of adoption and wordof-mouth would gain more traction later in the adoption curve. The findings demonstrate that the opposite actually occurs in the case of permissionless blockchain-enabled platforms. As informants argued, permissionless networks grow more organically thanks to word-ofmouth communication, a good example of an influential bottom-up driving force. Indeed, participants in decentralised networks actively support blockchain solutions that are aligned with their core values.

The findings revealed how the technology is largely misunderstood, leading many to fail even to find a realistic use-case. While the literature and industry reports focus greatly on the characteristics of the technology and its potential application, experts emphasised that the development of a blockchain application calls for a careful assessment of the actual need of blockchain. In that sense, the focus should be placed on the desired outcome and value proposition, rather than on the underlying technology. In some way, the less blockchain is talked about, i.e. the more emphasis is put on the ground-breaking solutions it offers to traditional problems, the more the technology will become mainstream.

The literature review highlighted the absence of taxonomies, let alone standards. The findings recognised that a significant challenge for the community is to navigate ambiguity and diverging opinions, exemplified in the astonishing number of developments, projects and cryptocurrencies. For blockchain-enabled platforms to scale, reach a critical mass and reap network effects, a higher degree of convergence and standardisation appears to be a difficult, but necessary route.

Emerging technologies such as blockchain are characterised by a hype-curve associated with inflated expectations. The findings suggest that the period of disillusionment has helped reduce the number of speculative investors, leading to a "healthier" environment for the development of blockchain projects. The steady growth of blockchain applications, crypto-wallet owners and job openings [79], [99], [100] indicate that blockchain and the token economy are here to stay [78].

In short, the findings complemented the literature review substantively, shedding light on the challenges that blockchain-enabled platforms are facing today.

\section{B. Recommendations}

This section aims at providing practical recommendations with a dual focus on incumbents and startups based on the main development phases of blockchain-enabled platforms. The key components are summarised in Fig. 2.

\section{Research Phase}

\section{- Value proposition}

The very first consideration for managers thinking about developing a blockchain-enabled platform is to clearly define the problem to solve. Too often the hype around the blockchain and platforms lead executives and developers to rush into a solution. Blockchain and platforms are enablers, not ends in themselves. Blockchain developers and consultants should accompany their clients on refining the value proposition and empower managers to push back ill-defined problems.

Recognising that blockchain is a compound system to onboard, solutions should justify the need among players to leverage a blockchain-enabled platform considering its main characteristics: transparency, privacy, asset ownership, traceability, immutability, trust and decentralisation. ROI targets can help define realistic expectations on all sides. In doing so, a common understanding between industry experts and blockchain engineers is crucial to reveal the real business value derived from using blockchain.

To assess the suitability of blockchain, managers can rely on a decision tree tool [78] and the blockchain model Canvas [101] while keeping abreast of changes in the environment which might imply changes on the latter. The objective of the exercise is, in short, to respond to the question "why a blockchain-enabled platform?". A feasibility study might generate valuable insights into the latter question before moving forward.

Last but not least, incumbents can also consider organising a hackathon, essentially outsourcing the ideation and prototyping phases in a short event.

\section{- Strategy}

Building upon the initial idea, the founding team must first and foremost define a strategy. An important consideration when defining a blockchain-enabled platform strategy is whether to join an existing network or to build one. Either way, managers are advised to assess what kind of business may be cannibalised in the process.

Disruptive innovation theory recommends startups to design highly differentiated business models and incumbents to create new business units to explore new business models and foster innovation. Incumbents transitioning to a platform business model face specifi challenges that relate to the existing culture, norms and behaviour: change managers will be required to handle the challenge of contrasting organisational identities and business models.

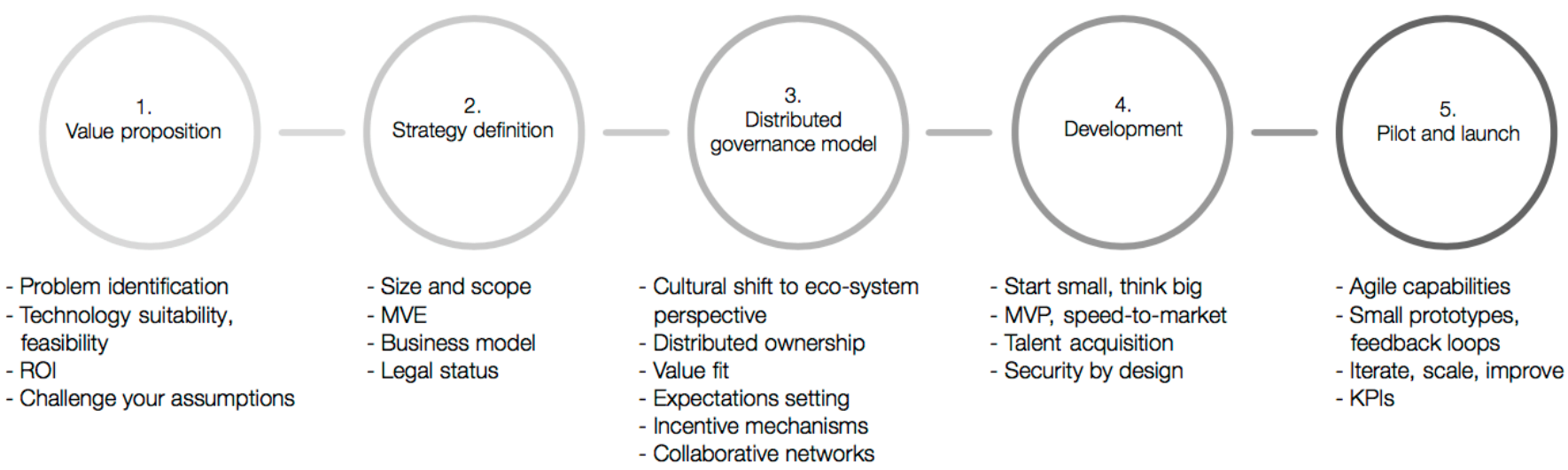

Fig. 2. Key success factors - Blockchain-enabled platforms. Source: autor based on research. 
Both startups and incumbents are recommended to rely on the expertise of BaaS and consultancy firms as these play an essential role in supporting entrepreneurs and incumbents on technical to strategic decisions.

\section{- Size and scope}

The strategy should consider early on the size and scope of the ecosystem to be created. Although blockchain-enabled platforms have the potential to scale globally, this may not be an objective. Managers are actually recommended to start operating in a controlled market and consider whether scalability is an objective right from the beginning, as this influences significantly technological choices. In this phase, managers need to define the desired requirements for the solution taking into account how these differ from an end-user or a business perspective. These requirements should be listed and organised by order of priority.

In starting in a controlled market, blockchain-enabled platforms developers are advised to refrain from radical positions on the decentralized debate and focus on developing commercial success. Once this is the case, migrating to a decentralized model and hence a much bigger ecosystem, can be considered. In short, attempting to go from a prototype to a global solution is too risky to be recommended, as the rate of failure of blockchain projects indicate.

Defining the MVE and the type of stakeholders expected in the ecosystem is the next part the strategy should cover, from end-users to investors, developers, volunteers, curators, moderators, validators, miners, etc. An important consideration is to assess the level of readiness of the different stakeholders, as these may introduce bottlenecks in the development or operation of the platform.

\section{- Governance}

Relatively quickly after the ideation process, the founding team should define the platform governance model. Mapping the transactions and disputes to arise between the stakeholders identified in the strategy is essential. On-chain processes, like consensus algorithms, are obvious choices to make early on depending on the strategy choices. Offchain processes are equally important, most notably in permissionless blockchains as these introduce a form of centralisation.

In defining the governance models, blockchain-enabled platform managers may want to consider the legal status of the company behind the platform, and whether a separate entity such as a foundation might be useful or not.

For incumbents, it is important to recognise that although one company may have built the initial platform, for the ecosystem to use the platform, ownership of the latter may be distributed across stakeholders. In order to build collaborative capabilities and retain a sustainable competitive advantage, a cultural shift is required from the silo perspective into an ecosystem perspective. A formal collaboration agreement can secure stakeholder commitment.

Expectation setting is crucial as participants are expected to agree on the provision of resources to build the platform. The founding team would set-up dedicated teams with a driving spirit to make collaboration successful. Without a formal hierarchy, these "self-managed" teams would need to pay great attention to pitfalls of group dynamics such as peer pressure, fear of judgement and groupthink. Diversity being important to spark creativity, the inclusion of minorities such as women and non-technical professionals can contribute to diversify the blockchain ecosystem and therefore reduce the risk of group bias [59].

A decentralised governance model should take into account the following: participants in decentralised platforms tend to place great importance to the value fit with the platform. Managers should beware of potential conflicts of interest that may arise between the platform, its users and those who initiated the project.

\section{- Incentivization strategies}

Defining incentives for all stakeholders of the ecosystem is critical in ensuring the long-term success of the latter. Permissioned blockchain-enabled platform managers may consider the advantages of traditional seed funding before jumping into tokenization and ICOs, notably when computer illiterate customers are part of the stakeholders.

Tokenization drivers should stem from the governance model and platform objectives and be built into the platform's rules. There is no simple straightforward formula, aside from the fact that constituents need to be involved early on in the incentivization strategy.

Incentive mechanisms should also reward third-party volunteers in critical functions. Notably, there should be incentives for curators, as the ability for decentralised platforms to enhance relevance of listings is key to the user experience and competition with giants like Amazon.

When approaching investors or clients, emphasis should be placed on the value of the solution and not on the underlying technology. However, from an end-user perspective, some solutions would require users to hold tokens and be familiar with the blockchain. The development of educational initiatives is advised to increase user engagement in projects. Teaser Apps can bring tokenization and blockchain closer to people's lives.

Last, a well-rounded communication strategy can help incumbents position their solution, but most importantly build community support. Leveraging word-of-mouth right from the start, by being transparent on values and objectives, proved to be a successful communication tactic for startups.

\section{Development Phase}

\section{- Collaborative networks}

Incumbents are recommended to foster innovation outside their own innovation labs. Intercompany collaboration allows to explore new ways of value creation. A key advantage for incumbents is their customer base, trust and credibility. However, incumbents are recommended not to overestimate the innovation efforts and perceive innovation as a journey not a destination. To that respect, disruptive theory recommends not to focus on the short-term results achieved [28], and incumbents are therefore particularly encouraged to assign to those projects a budget independent from short term ROI.

Top management support also appeared as a key ingredient and particularly relevant for large organisations to build an army of volunteers within the company that would advocate for a cultural change and reduce resistance.

\section{- Finding and retaining talent}

Blockchain development skills are scarce. Whilst incumbents can rely on traditional extrinsic motivators to attract and retain talent, from benefits to mentoring programmes and trainings, startups may use other arguments like equity and impact. Strong emphasis can be put on the mission pursued by the startup and leverage the importance that millennials, a large portion of the blockchain development workforce, give to the cultural fit [91].

Given the scarcity of talent, both startups and incumbents may consider relying on collaborative networks beyond company and industry boundaries. Leveraging global communities of developers can be made possible with the right incentivization strategies.

Last but not least, third party contractors and BaaS companies offer on-demand expertise, although at higher premium.

\section{- Product development}

Managers are advised to release the product iteratively. For most entrepreneurs, speed-to-market is deemed more important than having the minimum characteristics for the desired solution, even if it means compromising on the research. There are major drawbacks to this approach: 
- first, speed-to-market is dependent upon partners' readiness, an issue considering heterogeneous datasets and interoperability costs.

- second, speed-to-market can prove to be a limitation to securing the code. Security considerations are to be discussed early on, notably when it comes to the sensitivity or personal nature of the data to be stored on the blockchain.

- third, the pace of development of the technology calls for flexibility in the coding practices, so as for developers to avoid spending most of their time rewriting their code when the underlying technology changes.

Although it is indeed recommended to develop blockchain-enabled platforms in an agile, iterative process, releasing feature after feature and building the customer base gradually, this paper suggests that the research phase should not be compressed.

\section{- Securing by design}

Trust is essential in blockchain. Security breaches have profound consequences. As a result, both incumbents and startups should avoid storing sensitive data on any blockchain. The regulatory obligations are just too unclear at the moment to take any chance, given the immutable nature of distributed ledgers.

Startups in particular should pay close attention to their operational security practices, most particularly in terms of credentials management. Defining early on a risk management and a contingency plan, including forks, is also recommended.

Last but not least, given the transparent nature of blockchain code and in particular smart contracts, it is of utmost importance for developers to procure third-party code-auditing for vulnerabilities.

\section{Pilot and Launch Phases}

\section{- Regulatory considerations}

Before launching a blockchain-enabled platform in a given market, it is strongly recommended to seek legal advice. National legislation on crypto-projects differs greatly [102]. As such, it may be worth launching the platform in a given jurisdiction where the local authorities are supportive of the project, involving them into the project might be a way to achieve this.

\section{- Testing, validation and improvement}

Managers are advised to test small prototypes with a subset of customers within a controlled market. In order to enhance customer experience and satisfy evolving customer requirements, managers are highly encouraged to create feedback loops as suggested by the Lean Startup approach [51].

Last but not least, managers are advised to monitor the developments and develop a set of KPIs to monitor platform growth. Metcalfe's law can support on the definition of key performance indicators, in light of the ROI and development timeline previously defined.

\section{CONCLUSION}

Blockchain-enabled platforms have the potential to become no less than the guardians of a post-capitalist world order. The path towards such a bold vision is filled with obstacles, some of which are revealed in this paper. Despite the numerous efforts from scholars and practitioners to demystify blockchain, it remains obscure for most, even those developing blockchain-enabled platforms. Part of this stems from the diverging nature of the technology at the time of writing, leading the vast majority of blockchain projects to fail. Whilst technological convergence will come with time and commercial successes, the failure rate is amplified by a myriad of factors that can actually be tackled today.
Managing expectations is paramount given the vision stated above. Doing so requires a focus on the value proposition of the platform, rather than on the underlying technology. Defining the strategy, governance, size and incentives for the platform is also important before rushing into development. Following this approach should entice startups pursuing disruption through scalability, to paradoxically control growth, and even to make temporary concessions on key blockchain characteristics such as decentralization. Indeed, it is highly probable that the ecosystem stakeholders are simply not ready to operate in a fully decentralized model. Incumbents, on the other hand, need to reconcile with the larger implications of blockchain and embrace new management practices applicable to distributed ecosystems. If not managed properly, the risks are also notable for incumbents, as blockchain-enabled platforms introduce new ways of doing business that can question, if not cannibalize, existing ones.

Actually, developing a blockchain-enabled platform brings about a set of challenges stemming notably from the technology and the skills shortage. Collaborative networks are particularly useful yet difficult to apprehend for traditional actors when it comes to software development, as conflicting interests may arise. Retaining talent in such competitive market can also prove difficult, and open communication on a project's objectives and team values can be determining factors in ensuring a stable workforce in the development phase. Last but not least, uncertainty around regulation calls for caution when launching blockchain-enabled platforms and partnering with well-established stakeholders can reassure investors and regulators.

As the technology progresses and converges, taxonomies will emerge, and further research will shed light on key factors leading to commercial success. With time, managing bias will also be easier, as the enthusiasm depicted by most interviewees certainly exacerbated their perception of the potential and challenges of blockchain-enabled platforms. Particular areas of interest for research will be the actual implementation of decentralized governance models through on and off-chain mechanisms, balancing transparency and privacy, and leveraging collaborative dynamics for the development of blockchainenabled platforms.

This paper and future research will help clear the path for blockchainenabled platforms to become not only a reality, but a better one.

\section{APPENDIX}

\section{A. Appendix A: Data Collection}

\begin{tabular}{|c|c|}
\hline Period & April 2018 - February 2019 \\
\hline Data sources & 20 semi-structured interviews and conferences \\
\hline $\begin{array}{l}\text { Interviews } \\
\text { Type of } \\
\text { organisations }\end{array}$ & $\begin{array}{ll}\text { Incumbents: } 4 & \text { Startups: } 6 \\
\text { BaaS: } 3 & \text { Consultants: } 6 \\
\text { Academia: } 1 & \end{array}$ \\
\hline Gender & $60 \%$ males, $40 \%$ females \\
\hline Job titles & $\begin{array}{l}\text { Professor FinTech Professor } \\
\text { Founder/Partner } \\
\text { CEO } \\
\text { Head of Research and Development } \\
\text { Blockchain engineer } \\
\text { Senior Regulatory Officer } \\
\text { CTO } \\
\text { Head of Sales } \\
\text { Product Manager } \\
\text { Data Scientist } \\
\text { Head of Innovation and Digital Tranformation } \\
\text { Director of Partnerships }\end{array}$ \\
\hline Location & $\begin{array}{l}\text { US (5), UK (4), Belgium (2), Netherlands (2), Spain (2), } \\
\text { Austria (1), Canada (1), France (1), Germany (1) and } \\
\text { Switzerland (1). }\end{array}$ \\
\hline
\end{tabular}




\section{B. Appendix B: Blockchain-Enabled Platforms Challenges and} Recommendations

\section{Research Phase}

\begin{tabular}{|l|l|}
\hline Challenge & Recommendations \\
\hline $\begin{array}{l}\text { The innovation potential of } \\
\text { blockchain is debated. }\end{array}$ & $\begin{array}{l}\text { - Startups and incumbents have different } \\
\text { views on the innovative nature of } \\
\text { blockchain-enabled platforms from } \\
\text { moving foward. } \\
\text { - Disruptive innovation recommends } \\
\text { startups to design highly differentiated } \\
\text { business models; and incumbents } \\
\text { to create separate business units to } \\
\text { explore and drive innovation. }\end{array}$ \\
\hline $\begin{array}{l}\text { Misguided and misguiding } \\
\text { managers lead many platforms } \\
\text { to fail. }\end{array}$ & $\begin{array}{l}\text { Have management define objetives } \\
\text { and ROI timeline precisely before } \\
\text { jumping into development phase. }\end{array}$ \\
$\qquad \begin{array}{l}\text { Assess wether blockchain is the most } \\
\text { suitable technology for the problem } \\
\text { at hand. } \\
\text { - Learn to say no; push back misguided } \\
\text { requests from management. } \\
\text { - Do a feasibility study for instance } \\
\text { relying on a consultancy firm. } \\
\text { - Start with a proof-of-concept and } \\
\text { iterate development. } \\
\text { - Consider organising a hackathon. }\end{array}$ \\
\hline
\end{tabular}

\section{Development Phase}

\begin{tabular}{|c|c|}
\hline Challenge & Recommendations \\
\hline $\begin{array}{l}\text { Blockchain-enabled platform } \\
\text { face new and unique governance } \\
\text { issues. }\end{array}$ & $\begin{array}{l}\text { - Define governance model before } \\
\text { developing technology stack, and no } \\
\text { just consensus algorithms. } \\
\text { - Map the types of stakeholders } \\
\text { expected in the ecosystem and the } \\
\text { types of transactions and disputes that } \\
\text { will arise. } \\
\text { - Consider on and off-chain processes, } \\
\text { notably for platform development } \\
\text { decisions and for dispute resolution. } \\
\text { - Consider the legal status of the } \\
\text { company behind the platform, and } \\
\text { wether a separate entity such as } \\
\text { a foundation might be useful for } \\
\text { governance purposes. } \\
\text { - For incumbents, accept that although } \\
\text { one company may have built the initial } \\
\text { platform, for the ecosystem to use tha } \\
\text { plataform, ownership of the latter may } \\
\text { be distributed across stakeholders. }\end{array}$ \\
\hline $\begin{array}{l}\text { The skills required to develop } \\
\text { blockchain-enabled platforms } \\
\text { are diverse, scarce, and under } \\
\text { stress. }\end{array}$ & $\begin{array}{l}\text { - Startups should communicate openly } \\
\text { about their objetives, values and } \\
\text { culture, so as to attract talent who } \\
\text { value fit more than benefits. } \\
\text { - Incumbents can increase talent pool by } \\
\text { creating a mentorship programme and } \\
\text { bringing in traditional developers to be } \\
\text { mentored by blockchain experts. } \\
\text { - Startup and incumbents can rely } \\
\text { on collaborative networks beyond } \\
\text { company and industry boundaries. } \\
\text { - Third-party contractors and } \\
\text { Blockchain-as-a-service companies } \\
\text { offer on-demand expertise, although at } \\
\text { higher premium. }\end{array}$ \\
\hline
\end{tabular}

\begin{tabular}{|l|l|}
\hline Challenge & Recommendations \\
\hline $\begin{array}{l}\text { The security implications } \\
\text { of blockchain are largely } \\
\text { overlooked. }\end{array}$ & $\begin{array}{l}\text { - Avoid at all cost storing sensitive data } \\
\text { on blockchain. }\end{array}$ \\
& $\begin{array}{l}\text { - Develop early on operational security } \\
\text { procedures, notably in terms of } \\
\text { credential management. }\end{array}$ \\
- Develop early on a risk management \\
plan, defining the risk profile and \\
potential threats.
\end{tabular}

\section{Pilot and Launch Phases}

\begin{tabular}{|c|c|}
\hline Challenge & Recommendations \\
\hline $\begin{array}{l}\text { The mass adoption of } \\
\text { blockchain-enabled platforms } \\
\text { is constrained by exogenous } \\
\text { challenges such as regulatory } \\
\text { divergence and access to vital } \\
\text { financial services. }\end{array}$ & $\begin{array}{l}\text { - Seek legal advice. } \\
\text { - Start small, possibly within a confined } \\
\text { jurisdiction. } \\
\text { - Consider involving national authorities } \\
\text { in project. } \\
\text { - Consider registering platform in a } \\
\text { country where regulation and financial } \\
\text { system is supportive. } \\
\text { - Plan early for actual payment } \\
\text { processes for operational expenditures. }\end{array}$ \\
\hline $\begin{array}{l}\text { The mass adoption of } \\
\text { blockchain-enabled platforms } \\
\text { is contrained by endogenous } \\
\text { challenges such as crypto } \\
\text { volatility and digital divide. }\end{array}$ & $\begin{array}{l}\text { - Allow users in a platform to redeern } \\
\text { tokens with flat currencies to make } \\
\text { it more usable and last, to diversify } \\
\text { crypto portfolios with asset-backed } \\
\text { securities and hedge the market with } \\
\text { stablecoins to minimise the effects of } \\
\text { crypto price volatility and ultimately } \\
\text { protect the capital raised in the form } \\
\text { of cryptos. } \\
\text { - Simplify access to platform services; } \\
\text { train users; edutainment, etc. }\end{array}$ \\
\hline $\begin{array}{l}\text { Incentives strategies and } \\
\text { mechanisms for the launch, } \\
\text { development and operation of } \\
\text { blockchain-enabled platforms } \\
\text { are still exploratory. }\end{array}$ & $\begin{array}{l}\text { - Consider advantages of traditional } \\
\text { seed funding before jumping into } \\
\text { tokenization and ICOs, notably when } \\
\text { it comes to reassuring traditional } \\
\text { customers. } \\
\text { - Consider the different incentive } \\
\text { strategies for the different types of } \\
\text { stakeholders, from early investors to } \\
\text { miners, moderators and end-users. } \\
\text { - Define a communication strategy and } \\
\text { build community support, notably } \\
\text { leveraging word-of-mouth at the } \\
\text { beginning for startups. }\end{array}$ \\
\hline
\end{tabular}


ACKNOWLEDGMENT

I would like to express my gratitude to my husband, children and mother, for their active support throughout my studies. I also wish to thank everyone in the blockchain community who contributed to my research, for their availability and openness. Lastly, I would like to extend my sincere appreciation to Dr. Pinar Ozcan and Dr. Philip Drew for their guidance.

\section{REFERENCES}

[1] Cohen, B., Ernesto Amoros, J. \& Lundy, L. (2017) The generative potential of emerging technology to support startups and new ecosystems. Kelley School of Business, Indiana University. Business Horizons, 60: 741-745. [online] Available from: https://doi.org/10.1016/j.bushor.2017.06.004

[2] Reillier, L. C. \& Reillier, B. (2017) Platform strategy: how to unlock the power of communities and networks to grow your business. London: Routledge. [online] Available from: https://doi. org/10.4324/9781315598949

[3] Puschmann, T. \& Alt, R. (2016) Sharing Economy. Business and Information Systems Engineering, 58 (1): 93-99. [online] Available from: https://doi.org/10.1007/s12599-015-0420-2

[4] Friedman, M. (1999) Milton Friedman predicts the rise of Bitcoin in 1999! Youtube. [online] Available from: https://www.youtube.com/ watch? $=6$ MnQJFEVY7s

[5] Devaney, J. (2017) Blockchain and a Renaissance of the Social Commons. Huffpost. [online] Available from: https://www.huffingtonpost. com/entry/blockchain-and-a-renaissance-of-the-social-commons us_5a4462c2e4b0d86c803c74f0

[6] Burniske, C. \& Tatar, J. (2018) Cryptoassets: The Innovative Investor's Guide to Bitcoin and Beyond. McGraw-Hill Education.

[7] Swan, M. (2015) Blockchain: Blueprint for a New Economy. Sebastopol, CA: O'Reilly Media.

[8] Atzori, M. (2015) Blockchain Technology and Decentralized Governance: Is the State Still Necessary? [online] Available from: http://dx.doi. org/10.2139/ssrn.2709713

[9] Dalton-Homes, C. (2018) The Vital Role of Trust in Marketing. Script Consulting. [online] Available from: http://scriptconsulting.co.uk/blog/ category/all

[10] Schwab, K. (2016) The Fourth Industrial Revolution. World Economic Forum, Geneva: Penguin.

[11] Schwab, K. (2019) A New Architecture for the Fourth Industrial Revolution. Foreign Affairs. [online] Available from: https://www. foreignaffairs.com/articles/world/2019-01-16/globalization-40

[12] James, A. (2018) $92 \%$ of blockchain projects have already failed, average lifespan of 1.22 years. Bitcoinst.com. [online] Available from: https:// bitcoinist.com/92-blockchain-projects-already-failed-average-lifespan-122-years/

[13] Nakamoto, S. (2008) Bitcoin: A Peer-to-Peer Electronic Cash System. [online] Available from: https://bitcoin.org/bitcoin.pdf

[14] Muzammal, M., Qu, Q. \& Nasrulin, B. (2019) Renovating blockchain with distributed databases: An open source System. Future Generation Computer Systems, 90: 105-117.

[15] Pinna, A. \& Ruttenberg, W. (2016) Distributed Ledger Technologies in Securities Post-Trading Revolution or Evolution? ECB Occasional Paper No. 172. [online] Available from: https://www.ecb.europa.eu/pub/pdf/ scpops/ecbop172.en.pdf

[16] Malki, A. \& Weiss, M. B. H. (2016) Automating Ex-Post Enforcement for Spectrum Sharing: A New Application for Block-Chain Technology. [online] Available from: https://ssrn.com/abstract=2754111 or http:// dx.doi.org/10.2139/ssrn.2754111

[17] Tapscott, D. \& Tascott, A. (2016) The Impact of the Blockchain Goes Beyond Financial Services. Harvard Business Review. [online] Available from: https://hbr.org/2016/05/the-impact-of-the-blockchain-goes-beyondfinancial-services

[18] Chameau, J.L., Ballhaus, W.F. \& Lin, H.S (2014) Emerging and Readily Available Technologies and National Security: A Framework for Addressing Ethical, Legal, and Societal Issues. Washington (DC): National Academies Press (US); 2, Foundational Technologies. [online]
Available from: https://www.ncbi.nlm.nih.gov/books/NBK216326/

[19] Iansiti, M., \& Lakhani, K. (2017) The truth about blockchain. Harvard Business Review, 95 (1): 118-127. [online] Available from: https://hbr. org/2017/01/the-truth-about-blockchain

[20] MacDonald, T.J., Allen, D.W.E. \& Potts, J. (2016) Blockchains and the Boundaries of Self-Organized Economies: Predictions for the Future of Banking. In: Tasca P., Aste T., Pelizzon L., Perony N. (eds) Banking Beyond Banks and Money. New Economic Windows. Springer, Cham. [online] Available from: https://link.springer.com/content/ pdf/10.1007\%2F978-3-319-42448-4.pdf

[21] Olleros, F. X. \& Zhegu, M. (2016) Research Handbook on Digital Transformations. Université du Québec: Montreal. Edward Elgar Publishing Limited

[22] Peters G.W. \& Panayi E. (2016) Understanding Modern Banking Ledgers Through Blockchain Technologies: Future of Transaction Processing and Smart Contracts on the Internet of Money. In: Tasca P., Aste T., Pelizzon L., Perony N. (eds) Banking Beyond Banks and Money. New Economic Windows. Springer, Cham. [online] Available from: https://link.springer. com/content/pdf/10.1007\%2F978-3-319-42448-4.pdf

[23] Goorha, P. (2017) The Return of 'The Nature of the Firm': The Role of the Blockchain. The Journal of the British Blockchain Association, 1 (1): 1-5. [online] Available from: http://dx.doi.org/10.2139/ssrn.3080696

[24] Coase, R. H. (1937) The Nature of the Firm. Economica, 4 (16): 386405. [online] Available from: https://doi.org/10.1111/j.1468-0335.1937. tb00002.x

[25] Catalini, C. \& Gans, J.S. (2017) Some Simple Economics of the Blockchain. Rotman School of Management Working Paper No. 2874598; MIT Sloan Research Paper 5191 (16). [online] Available from: http:// dx.doi.org/10.2139/ssrn. 2874598

[26] Schaffers H. (2018) The Relevance of Blockchain for Collaborative Networked Organizations. In: Camarinha-Matos L., Afsarmanesh H., Rezgui Y. (eds) Collaborative Networks of Cognitive Systems. PRO-VE 2018. IFIP Advances in Information and Communication Technology, 534. Springer, Cham. [online] Available from: https://doi.org/10.1007/978-3319-99127-6_1

[27] Christensen, C. M. (2006) The Ongoing Process of Building a Theory of Disruption, Journal of Product Innovation Management, 23 (1): 39-55. [online] Available from: https://doi.org/10.1111/j.1540-5885.2005.00180.x

[28] Christensen, C. M., Raynor, M. \& McDonald, R. (2015) What Is Disruptive Innovation? Harvard Business Review, 93(12): 44-53.

[29] Rogers, E.M. (2003) Diffusion of innovations. 5th edt.

[30] Pickard, J., Angolia, M. \& Chou, T.S. (2018). IPV6 diffusion on the Internet reaches a critical point. Journal of Technology, Management, and Applied Engineering, 34: 1-17. [online] Available from: https://www.researchgate. net/publication/323416689_IPV6_diffusion_on_the_Internet_reaches_a critical_point

[31] Cheah, E. T. \& Fry, J. (2015) Speculative bubbles in Bitcoin markets? An empirical investigation into the fundamental value of Bitcoin. Economic Letters, 130: 32-36. [online] Available from: https://doi.org/10.1016/j. econlet.2015.02.029

[32] Böhme, R., Christin, N., Edelman, B. \& Moore, T. (2015) Bitcoin: Economics, Technology, and Governance. Journal of Economic Perspectives, 29 (2): 213-38. [online] Available from: https://www. aeaweb.org/articles?id=10.1257/jep.29.2.213

[33] Orcutt, M. (2019) In 2019, blockchains will start to become boring. MIT Technology Review. [online] Available from: https://www. technologyreview.com/s/612687/in-2019-blockchains-will-start-tobecome-boring/

[34] Gartner (2019) Gartner 2019 Hype Cycle Shows Most Blockchain Technologies Are Still Five to 10 Years Away From Transformational Impact. Gartner. [online] Available from: https://www.gartner.com/en/ newsroom/press-releases/2019-10-08-gartner-2019-hype-cycle-showsmost-blockchain-technologies-are-still-five-to-10-years-away-fromtransformational-impact

[35] Morecroft, J.D.W. (2015) Chapter 6: The Dynamics of Growth from Diffusion. Strategic Modelling and Business Dynamics + Website: A Feedback Systems Approach. John Wiley \& Sons, Incorporated, New York. [online] Available from: https://ebookcentral.proquest.com/lib/ warw/reader.action?docID $=1895653$

[36] Jeyaraj, A. Rottman, J. W \& Lacity, M. C. (2006) A review of the predictors, linkages, and biases in IT innovation adoption research. Journal 
of information technology, 21: 1-23. [online] Available from: https://doi. org/10.1057/palgrave.jit.2000056

[37] Lee, Y., Kozar, J.A. \& Larsen, K.R.T. (2003) The Technology Acceptance Model: Past, Present, and Future. Communications of the Associations for Informations Systems, 12, (50): 752-780. [online] Available from: https:// aisel.aisnet.org/cais/vol12/iss1/50

[38] Alstyne, M., Parker, G., \& Choudary, S., (2016) Pipelines, Platforms, and the New Rules of Strategy. Harvard Business Review, 94 (4): 54-62.

[39] Altman, E. J. \& Tushman, M. L. (2017) Platforms, Open/User Innovation, and Ecosystems: A Strategic Leadership Perspective. Entrepreneurship, Innovation and Platforms, Advances in Strategic Management, Emerald Publishing Limited, 11: 177-207. [online] Available from: https://doi. org/10.1108/S0742-332220170000037007

[40] Adner, R. (2006) Match Your Innovation Strategy to Your Innovation Ecosystem. Harvard Business Review. [online] Available from: http:// sjbae.pbworks.com/w/file/fetch/60084211/Adner_2006_HBR.pdf

[41] Hill, L. A., Brandeau, G., Truelove, E. \& Lineback, K. (2014) Collective Genius. The art and practice of leading innovation. Harvard Business Review Press. Boston, Massachusetts.

[42] Utterback, J. M. \& Suarez, F. F. (1993) Innovation, competition, and industry structure. Research Policy, 2 (1): 1-21. [online] Available from: https://doi.org/10.1016/0048-7333(93)90030-L

[43] MacCormack, A., Forbath, T., Brooks, P. \& Kalaher, P. (2007) Innovation through Global Collaboration: A New Source of Competitive Advantage. Harvard Business School Working Paper 07-080. [online] Available from: http://citeseerx.ist.psu.edu/viewdoc/ download?doi $=10.1 \cdot 1.123 .1225 \&$ rep $=$ rep $1 \&$ type $=$ pdf

[44] Faems, D., Looy, B. V. \& Debackere, K. (2005) Interorganizational Collaboration and Innovation: Toward a Portfolio Approach. The Journal of Product Innovation Management, 22: 238-250. [online] Available from: https://doi.org/10.1111/j.0737-6782.2005.00120.x

[45] Venkatraman N. \& Henderson J.C. (2008) Four Vectors of Business Model Innovation: Value Capture in a Network ERA. In: Pantaleo D., Pal N. (eds) From Strategy to Execution. Springer, Berlin, Heidelberg.

[46] Chesbrough, H. W. (2003) The Era of Open Innovation. MIT Sloan Management Review, 44 (3). [online] Available from: https://eclass. uoa.gr/modules/document/file.php/ECON197/Papers\%20Strategy/ Chesbrough\%202003\%20The\%20Era\%20of\%20Open\%20Innovation. pdf

[47] Osterwalder, A. \& Pigneur, Y. (2010) Business Model Generation. A Handbook for Visionaries, Game Changers, and Challengers. Hoboken, New Jersey: John Wiley \& Sons.

[48] Rialti, R., Marzi, G., Silic, M. \& Ciappei, C. (2018) Ambidextrous organization and agility in big data era: The role of business process management systems. Business Process Management Journal, 24(5): 1091-1109. [online] Available from: https://doi.org/10.1108/BPMJ-072017-0210

[49] O'Reilly, C. A. \& Tushman, M. L. (2008) Ambidexterity as a dynamic capability: Resolving the innovator's dilemma. Elsevier: Research in Organizational Behavior, 28: 185-206. [online] Available from: https:// www.sciencedirect.com/science/article/pii/S0191308508000105

[50] Trimi, S. \& Berbegal-Mirabent, J. (2012) Business model innovation in entrepreneurship. International Entrepreneurship and Management Journal, 8: 449-465. [online] Available from: https://doi.org/10.1007/ s11365-012-0234-3

[51] Ries, E. (2011) The Lean Startup: How today's entrepreneurs use continuous innovation to create radically successful businesses. New York: Crown Publishing Group.

[52] Anjum, A., Sporny, M. \& Sill, A. (2017) Blockchain Standards for Compliance and Trust, in IEEE Cloud Computing, 4 (4): 84 90. [online] Available from: http://ieeexplore.ieee.org/stamp/stamp. jsp?tp $=$ \&arnumber $=8066010$ \&isnumber $=8065994$

[53] Van den Berg, G. \& Pietersma, P. (2015) Key Management Models 3rd Ed. Harlow, UK, Pearson Education Limited.

[54] Osterwalder, A., Pigneur, Y. \& Tucci, C. L. (2005) Clarifying Business Models: Origins, Present, and Future of the Concept. Communications of the Association for Information Systems: 16 (1). [online] Available from: https://aisel.aisnet.org/cais/vol16/iss1/1

[55] Osterwalder, A. \& Pigneur, Y. (2015) Business model report. Strategyzer. [online] Available from: https://assets.strategyzer.com/assets/resources/ business-model-report-2015.pdf
[56] Huertas, J. Liu, H. \& Robinson, S. (2018) Eximchain: Supply Chain Finance solutions on a secured public, permissioned blockchain hybrid. [online] Available from: https://www.eximchain.com/WhitepaperEximchain.pdf

[57] Lewrick, M., Link, P. \& Leifer, L. (2018) The Design Thinking Playbook: Mindful digital transformation of teams, products, services, businesses and ecosystems. Wiley: New Jersey.

[58] King, D. \& Lawley, S. (2013) Organisational Behaviour. Oxford: OUP

[59] Jan, Z., Third, A., Bachler, M. \& Domingue, J. (2018). Peer-reviews on the blockchain. In: RefResh 2018:1st Workshop on Reframing Research, Cologne, Germany. [online] Available from: http://oro.open. ac.uk/58593/1/Peer_reviews_on_the_blockchain.pdf

[60] Macedo, P., \& Camarinha-Matos, L., (2017) Value systems alignment analysis in collaborative networked organizations management. Applied Sciences, 7 (12): 1231. [online] Available from: www.mdpi.com/2076$3417 / 7 / 12 / 1231 / \mathrm{pdf}$

[61] Courtois, N.T. (2016) Features or Bugs: The Seven Sins of Current Bitcoin. In: Tasca P., Aste T., Pelizzon L., Perony N. (eds) Banking Beyond Banks and Money. New Economic Windows. Springer, Cham. [online] Available from: https://doi.org/10.1007/978-3-319-42448-4 6

[62] Scott, B. (2016) How Can Cryptocurrency and Blockchain Technology Pay a Role in Building Social and Solidarity Finance?. United Nations Research Institute for Social Development. [online] Available from: http:// hdl.handle.net/10419/148750

[63] Yermack, D. (2017) Corporate Governance and Blockchains. Review of Finance, 21: 7-31. [online] Available from: https://doi.org/10.1093/rof/ rfw074

[64] Srinivasan, R., Lilien, G. L. \& Rangaswamy, A. (2004) First in, First out? The Effects of Network Externalities on Pioneer Survival. Journal of Marketing, 68 (1): 41-58. [online] Available from: http://journals.ama.org/ doi/abs/10.1509/jmkg.68.1.41.24026

[65] Dixon, C. (2017) Crypto Tokens: A Breakthrough in Open Network Design. Medium. [online] Available from: https://medium.com/@cdixon/ crypto-tokens-a-breakthrough-in-open-network-design-e600975be2ef

[66] Alabi, K. (2017) Digital blockchain networks appear to be following Metcalfe's Law. Electronic Commerce Research and Application. [online] Available from: https://doi.org/10.1016/j.elerap.2017.06.003.

[67] Wheatley, S., Sornette, D., Huber, T., Reppen, M., \& Gantner, R. N. (2018) Are Bitcoin Bubbles Predictable? Combining a Generalized Metcalfe's Law and the LPPLS Model. Swiss Finance Institute Research Paper: 1822. [online] Available from: http://dx.doi.org/10.2139/ssrn.3141050

[68] Katz, Michael L., and Carl Shapiro. 1994. Systems Competition and Network Effects. Journal of Economic Perspectives, 8 (2): 93-115. DOI: 10.1257/jep.8.2.93

[69] Gandal, N. \& Halaburda, H. (2016) Can We Predict the Winner in a Market with Network Effects? Competition in Cryptocurrency Market. [online] Available from: https://www.mdpi.com/2073-4336/7/3/16/htm

[70] Evans, D. S. \& Schmalensee, R. (2010) Failure to Launch: Critical Mass in Platform Businesses. Review of Network Economics, 9 (4). [online] Available from: https://doi.org/10.2202/1446-9022.1256

[71] Evans, P., Aré, L., Forth, P., Harlé, N. \& Portincaso, M. (2016) Thinking outside the blocks: A Strategic Perspective on Blockchain and Digital Tokens. The Boston Consulting Group. [online] Available from: http:// media-publications.bcg.com/BCG-Thinking-Outside-the-BlocksDec-2016.pdf

[72] Rauchs, M., Glidden, A., Gordon, B., Pieters, G., Recanatini, M. Rostand, F., Vagneur, K. \& Zhang, B. (2018) Distributed Ledger Technology Systems: A Conceptual Framework. Cambridge Centre for Alternative Finance. University of Cambridge. [online] Available from: https://www. jbs.cam.ac.uk/fileadmin/user_upload/research/centres/alternative-finance/ downloads/2018-10-26-conceptualising-dlt-systems.pdf

[73] Pazaitis, A., De-Filippi, P. and Kostakis, V. (2017) Blockchain and value systems in the sharing economy: The illustrative case of Backfeed. Technological Forecasting and Social Change, 125: 105-115. [online] Available from: https://doi.org/10.1016/j.techfore.2017.05.025

[74] Carson, B. Romanelli, G., Walsh, P. \& Whumaev, A. (2018) Blockchain beyond the hype: What is the strategic business value? McKinsey \& Company. [online] Available from: https://www.mckinsey.com/businessfunctions/digital-mckinsey/our-insights/blockchain-beyond-the-hypewhat-is-the-strategic-business-value

[75] Ray, J. (2019) On sharding blockchains. Github. [online] Available 
from: https://github.com/ethereum/wiki/wiki/Sharding-FAQs\#howdoes-plasma-state-channels-and-other-layer-2-technologies-fit-into-thetrilemma

[76] Liu, C. (2019) Solving the scalability trilemma: collaborative blockchains in 2019. Crypto Briefing. [online] Available from: https://cryptobriefing. com/scalability-trilemma-collaborative-blockchains/

[77] Lin, I.C. \& Liao, T.C. (2017) A Survey of Blockchain Security Issues and Challenges. International Journal of Network Security, 19 (5): $653-$ 659. [online] Available from: https://pdfs.semanticscholar.org/f61e/ db500c023c4c4ef665bd7ed2423170773340.pdf

[78] Mulligan, C., Scott, J. Z., Warren, S. \& Rangaswami, J.P. (2018) Blockchain beyond the hype: A practical framework for business leaders. World Economic Forum and Imperial College London. [online] Available from: http://www3.weforum.org/docs/48423_Whether_Blockchain WP.pdf

[79] Swissborg (2019) Crypto Market Review 2018. Swissborg. [online] Available from: https://docsend.com/view/9pda6eq

[80] Malgieri, G. \& Custers, B. (2017) Pricing privacy - the right to know the value of your personal data. Computer Law and Security Review, 34 (2): 289-303. [online] Available from: https://www.sciencedirect.com/science/ article/pii/S0267364917302819

[81] Angelis, J. \& Ribeiro da Silva, E. (2016) Blockchain adoption: A value driver perspective. Business Horizons.

[82] Ethereum (2019) Ethereum: Blockchain App Platform. [online] Available from: https://www.ethereum.org

[83] Mustonen-Ollila, E. \& Lyytinen, K. (2003) Why organizations adopt information system process innovations: a longitudinal study using Diffusion of Innovation theory. Information Systems Journal, 13: 275-297. [online] Available from: https://doi.org/10.1046/j.13652575.2003.00141.x

[84] Biggam, J (2013) Succeeding with your Master's Dissertation, A step-bystep handbook. McGraw Hill Education: Berkshire, England.

[85] Bryman, A. \& Bell, E. (2015) Business Research Methods. Oxford: Oxford University Press.

[86] Ozcan, P. (2018) Growing with the Market? How Changing Conditions during Market Growth Affect Interfirm Ties. Strategic Management Journal, 39 (2): 295-328. [online] Available from: https://doi.org/10.1002/ smj. 2740

[87] Jick, T.D.(1979) Mixing qualitative and quantitative methods: triangulation in action. Administrative Science Quarterly, 24 (4): 602-611. [online] Available from: https://www.jstor.org/stable/2392366?seq=1\#page_scan_ tab_contents

[88] Bogdan, R. C. \& Biklen, S. K. (1997) Qualitative Research for Education. Boston, MA: Allyn \& Bacon.

[89] Ozcan, P., Han, S. \& Graebner, M. E. (2017) Single cases: the what, why, and how. In: Mir, Raza A. and Jain, Sanjay, (eds.) The Routledge companion to qualitative research in organization studies. New York: Routledge: 92-112. [online] Available from: https://www.worldcat.org/ title/routledge-companion-to-qualitative-research-in-organization-studies/ oclc/1002303954\&referer $=$ brief results

[90] Eisenhardt, K. M. \& Graebner, M. E. (2007) Theory Building from Cases: Opportunities and Challenges. The Academy of Management Journal, 50 (1): 25-32. [online] Available from: http://www.jstor.org/stable/20159839

[91] Gianniris, D. (2018) The Millennial Arrival And The Evolution Of The Modern Workplace. Forbes. [online] Available from: https://www.forbes. $\mathrm{com} / \mathrm{sites} /$ forbestechcouncil/2018/01/25/the-millennial-arrival-and-theevolution-of-the-modern-workplace/\#2a17259e5a73/

[92] Ross, A. (2018) Will blockchain solve the cyber security skills crisis? Information Age. [online] Available from: https://www.information-age. com/blockchain-cyber-security-skills-crisis-2-123472476/

[93] Burg, J. Murphy, C. \& Pétraud, J.P. (2018) Blockchain for International Development: using a learning agenda to address knowledge gaps. MERL Tech.[online] Available from: http://merltech.org/blockchainfor-international-development-using-a-learning-agenda-to-addressknowledge-gaps/

[94] Janus, E. (2018) Is Blockchain just hot air? New study finds zero percent success rate. Bitcoinist, Cryptocurrency news and technology. [online] Available from: https://bitcoinist.com/blockchain-study-zero-percentsuccess/

[95] Rancea, B. (2019) What is Ethereum Governance? Complete Beginner's
Guide. Unblock. [online] Available from: https://unblock.net/what-isethereum-governance/

[96] Dyhrberg A.H. (2016) Bitcoin, gold and the dollar-A GARCH volatility analysis. Finance Research Letters, 16: 85-92. [online] Available from https://www.sciencedirect.com/science/article/pii/S1544612315001038

[97] Tasca, P., Hayes, A. \& Liu, S., (2018) The evolution of the bitcoin economy: Extracting and analyzing the network of payment relationships. The Journal of Risk Finance, 19 (2): 94-126. [online] Available from: https://doi.org/10.1108/JRF-03-2017-0059

[98] Wilmoth, J. (2019) Almost Lost My Business: Bitcoin Entrepreneurs Sound Off on Banking Struggles. Cnn. [online] Available from: https:// www.ccn.com/bitcoin-entrepreneurs-banking-struggles

[99] Blockchain (2019) Blockchain charts. Blockchain. [online] Available from: https://www.blockchain.com/en/charts/my-wallet-n-users

[100] Willms, J. (2018) Report: Despite Price Volatility Blockchain and Crypto Jobs are In Demand. Bitcoin Magazine. [online] Available from: https:// bitcoinmagazine.com/articles/report-despite-price-volatility-blockchainand-crypto-jobs-are-demand/

[101] Chikara, A. (2019) Blockchain Canvas. 3 Pillar Global. [online] Available from: $\quad$ https://www.3pillarglobal.com/wp-content/uploads/2015/11/ blockchain-canvas_final.png

[102] Kent, C. and Jarvis, S. (2017) Divergent Regulatory Approaches to Cryptocurrency Offerings: Developments in Canada, the United States, and China. Capital Markets Bulletin. McMillan. [online] Available from: $\quad$ https://mcmillan.ca/Divergent-Regulatory-Approaches-toCryptocurrency-Offerings-Developments-in-Canada-the-United-Statesand-China

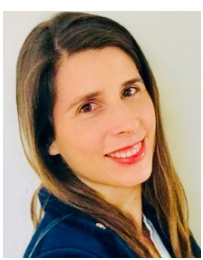

M. Inmaculada García Sáez

Inma García Sáez is a digital transformation professional with over a decade of operational experience in the financial and high-tech industries. She supports social innovation initiatives tackling global challenges, leveraging emerging technologies. Inma holds an MBA awarded with Distinction from Warwick Business School (United Kingdom). She also studied Digital Transformation and Innovation at INSEAD (France) and Business Administration at the University of Málaga (Spain). 